\title{
Résumés des POSTERS affichés au XXVème Congrès de la SALF
}

\author{
10-11 octobre 2008, Hammamet, Tunisie
}

\section{POSTER 11}

Anomalies chromosomiques et infertilité masculine : une série de 500 caryotypes

\section{N.B. ABDELMOULA1, A. AMOURI2, M. MEDDEB3, A.S. BEN HMIDA1, N. CHAKROUN FEKI1, T. REBAII1}

1 Laboratoire d'Histologie Faculté de Médecine de Sfax, Tunisie 2 Laboratoire de Cytogénétique, Institut Pasteur de Tunis, Tunisie 3 Laboratoire de Génétique, Tunis, Tunisie nouha_abdelmoulabouayed@yahoo.fr

Introduction : On estime à près de $10 \%$ la fréquence de l'infertilité masculine dans la population humaine. Une infertilité masculine est souvent liée à un déficit de quantité, de mobilité, de morphologie ou de fonctionnement des spermatozoïdes. Les causes de l'infertilité masculine sont multiples dont les facteurs chromosomiques et géniques. Globalement, la fréquence des anomalies chromosomiques dans la population des hommes ayant une concentration de spermatozoïdes inférieure à $10 \mathrm{millions} / \mathrm{ml}$ est multipliée par dix.

Matériel et Méthodes : Nous rapportons dans ce travail les résultats des études cytogénétiques pratiquées chez 500 hommes infertiles dont le spermogramme montre soit une altération de la numération des spermatozoïdes à type d'azoospermie ou d'oligospermie (associée ou non à une asthéno/tératospermie) soit uniquement une asthéno/tératospermie sévère et qui sont candidats à une ICSI.

Les analyses chromosomiques ont été menées selon la technique cytogénétique conventionnelle avec marquage chromosomique en bandes RHG et parfois GTG.

Résultats : Nous avons pu révéler ainsi 49 anomalies chromosomiques soit une fréquence globale de $9,54 \%$. Cette fréquence s'élève si on considère uniquement le groupe à risque des azoo-oligospermies. Elle serait de $21,16 \%$ en cas d'azoospermie chez qui les anomalies de nombre du chromosome $X$, avec formule $47, X X Y$ et syndrome de klinefelter, prédominaient. Les autres anomalies détectées correspondaient à : des males $\mathrm{XX}$, des anomalies de structure du chromosome $Y$, des translocations robertsoniennes. La fréquence des remaniements cytogénétiques était nettement plus faible au cours de l'oligospermie soit $5,6 \%$. La nature des anomalies était aussi différente avec prédominance des translocations équilibrées notamment de type réciproque.

Conclusion : Nos chiffres sont comparables à celles décrites dans la littérature, incitent à la considération de l'étude cytogénétique au cours du bilan d'infertilité masculine et justifient la pratique systématique du caryotype avant toute tentative de procréation médicalement assistée. En cas de remaniement, les patients doivent être bien informés des risques encourus par la descendance ainsi que de la baisse du taux de réussite en terme de fécondation, d'implantation et de grossesse au cours des procédures de PMA. L'alternative serait le recours à une prise en charge spécialisée faisant appel au diagnostic préimplantatoire.

\section{POSTER 12}

Intérêt du diagnostic préimplantatoire au cours de la prise en charge en PMA des translocations robertsoniennes : à propos d'une grossesse triple pour une $t(14 ; 21)$

\section{N.B. ABDELMOULA1, P. DEBECKER2, M. MEDDEB3, A. AMOURI4, T. REBAl1}

\author{
1 Laboratoire d'Histologie Faculté de Médecine de Sfax, Tunisie \\ 2 Centre de Génétique Médicale UZB Brussel, Belgique \\ 3 Laboratoire de Génétique, Tunis, Tunisie \\ 4 Laboratoire de Cytogénétique, Institut Pasteur de Tunis, Tunisie \\ nouha_abdelmoulabouayed@yahoo.fr
}

Introduction : Décrites par Robertson en 1916, les translocations robertsoniennes sont consécutives à la fusion de deux chromosomes acrocentriques dans leur région centromérique ou plus souvent juxtacentromèrique. Elles représentent le remaniement de structure le plus fréquemment rencontré dans la population humaine. Leur incidence globale à la naissance est estimée à $0,9-1,23 / 1000$ selon les séries. Des différentes variétés, la translocation trob $(13 ; 14)$ la translocation trob $(14 ; 21)$ sont les plus fréquentes. Quelque soit le type de la translocation robertsonienne, le chromosome transloqué est associé, en prophase de méiose I, avec ses deux homologues normaux en une configuration trivalente qui peut conduire à un déséquilibre de ségrégation. Ces translocations peuvent retentir plus ou moins gravement sur la qualité de la spermatogenèse et ont un rôle délétère concernant les résultats de la PMA.

Matériel et Méthodes : Nous rapportons l'observation clinique d'une translocation trob $(14 ; 21)$ familiale découverte chez deux frères qui consultent tous deux pour une infertilité primaire de plusieurs années associée à une azoospermie chez l'un et à une oligospermie extrême chez l'autre. Les deux couples avaient bénéficié de plusieurs tentatives d'ICSI classique sans résultats.

Résultats : L'un des deux couples pour lequel la femme âgée de 40 ans a pu bénéficier finalement d'une ICSI associée à un diagnostic préimplantatoire avec recueil de 5 embryons équilibrés. Après transfert de 3 embryons, une grossesse triple a été obtenue, actuellement à la 13 semaine. 
Conclusion : A travers de cette observation, nous discuterons l'intérêt du diagnostic préimplantatoire au cours de la prise en charge par PMA des translocations robertosniennes masculines.

\section{POSTER 13}

Facteurs de risque environnementaux de la cryptorchidie : étude cas-témoins

\section{T. ALMONTA, R. MIEUSSETA,B, P. THONNEAUA}

\author{
A Équipe de Recherche en Fertilité Humaine (EA 3694), Hôpital \\ Paule de Viguier, Toulouse \\ B Centre de Stérilité Masculine, Hôpital Paule de Viguier, \\ Toulouse almont.t@chu-toulouse.fr
}

Introduction : La cryptorchidie est la malformation congénitale la plus fréquente à la naissance (2 à $9 \%$ ) [1]. C'est, à ce jour, le seul facteur de risque identifié du cancer du testicule et un facteur de risque majeur de l'infécondité masculine $[2,3]$. Au cours des dernières décennies, une augmentation de l'incidence de la cryptorchidie a été observée dans plusieurs pays européens (Danemark, GrandeBretagne, Suède) $[4,5]$. L'hypothèse majeure soulevée par les anglosaxons pour expliquer cette récente augmentation est d'ordre environnementale. Les perturbateurs endocriniens auraient, par leurs propriétés oestrogéniques ou anti-androgéniques, la capacité de perturber les actions hormonales physiologiques [6-8]. Cette hypothèse environnementale constitue l'hypothèse de recherche de notre étude dont l'objectif est de mettre en évidence des facteurs de risque environnementaux de survenue de testicules en position cryptorchide par une étude rétrospective de type cas-témoins.

Matériel et Méthodes : Les cas sont constitués d'enfants (âgés de 14 à 36 mois) opérés d'une cryptorchidie et les témoins, d'enfants (de même tranche d'âge) opérés d'une autre pathologie dans le service de chirurgie pédiatrique de l'hôpital des enfants à Toulouse (CHU Purpan) de mars à décembre 2008. La voie veineuse déjà installée pour l'anesthésie générale sert à prélever $20 \mathrm{ml}$ de sang chez chaque enfant lorsqu'il est endormi. Les tubes de sang (anonymisés et étiquetés) sont acheminés dans le service de Biochimie du CHU Purpan de Toulouse (pour les dosages biologiques et hormonaux) et dans le service de Pharmacologie et Toxicologie du CHU Dupuytren de Limoges (pour les dosages toxicologiques pesticides ou leurs métabolites). Au décours de l'intervention chirurgicale de l'enfant, un questionnaire est soumis à la maman (emploi, prises thérapeutiques, mode de vie, etc.) par une personne agréée. Ce questionnaire sera complété des informations du dossier obstétrical quant aux thérapeutiques et à leur posologie administrées à la maman durant la grossesse.

Résultats attendus : Les résultats de cette recherche devraient permettre de confirmer (ou non) le rôle délétère des perturbateurs endocriniens sur la reproduction humaine masculine. Les conclusions de cette recherche sur les facteurs de risque de survenue de la cryptorchidie pourraient conduire à la mise en place de mesures préventives comme, par exemple, l'éviction des femmes enceintes vis-à-vis de certaines expositions ou comportements.

Discussion et Conclusion : Une telle recherche sur les pathologies uro-génitales du nouveau-né de sexe masculin permettra d'attirer l'attention de nos collègues cliniciens, obstétriciens et pédiatres, sur l'importance du diagnostic de cette malformation. Par ailleurs, ce projet de recherche s'inscrit dans une démarche d'identification et d'évaluation de certains risques environnementaux pour la santé humaine. La problématique abordée est celle de l'impact de facteurs environnementaux sur la fertilité humaine, qui constitue actuellement un enjeu majeur de santé publique.

Références bibliographiques :

[1] Berkovitz, G.D., Abnormalities of gonadal determination and differentiation. Semin Perinatol, 1992. 16(5): p. 289-98.

[2] Mieusset, $R$., et al., Cinical and biological characteristics of infertite men with a history of cryptorchidism. Hum Reprod, 1995. 10(3): p. 6139.

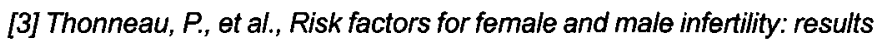
of a case-control study. Hum Reprod, 1992. 7(1): p. 55-8.

[4] Chivers, C., et al., Apparent doubling of frequency of undescended testis in England and Wales in 1962-81. Lancet, 1984.2(8398): p. 3302.

[5] Paulozzi, L.J., International trends in rates of hypospadias and cryptorchidism. Environ Health Perspect, 1999. 107(4): p. 297-302.

[6] Sharpe, R.M. and N.E. Skakkebaek, Are oestrogens involved in falling sperm counts and disorders of the male reproductive tract? Lancet, 1993. 341(8857): p. 1392-5.

[7] Newbold, R., Cellular and molecular effects of developmental exposure to diethylstilbestrol: implications for other environmental estrogens. Environ Health Perspect, 1995. 103 Suppl 7: p. 83-7.

[8] Paul, M., Occupational reproductive hazards. Lancet, 1997. 349(9062): p. $1385-8$

\section{POSTER 14}

Bilan biologique et facteurs pronostiques de la fécondation assistée par micro-injection (ICSI) chez des patients azoospermiques

\section{ANNABI, M. AJINA, A. CHAIB, M. MEHDI, S. IBALA, H. SAIDI, H. KHAIIRI,A. SAAD \\ Unité de Médecine de la Reproduction, Hôpital F.Hached de Sousse, Tunisie leilaelabed33@yahoo.fr}

Introduction : Depuis la découverte de l'ICSI (1992, Palermo) le pronostic de l'infécondité masculine a été complètement révolutionné. Le bilan de I'ICSI avec biopsie testiculaire est significativement plus faible que celui de l'ICSI avec sperme frais. Le but de cette étude a été d'établir le profil biologique des patients azoospermiques candidats à l'ICSI et de mettre en évidence les facteurs pronostiques chez ces patients.

Matériel et Méthodes : notre travail porte sur 22 couples inféconds dont les maris sont azoospermiques sécrétoires (27.3\%), excrétoires $(54.5 \%)$ et mixtes $(18.2 \%)$. Tous les patients ont bénéficié d'un bilan hormonal, un caryotype, une biochimie du sperme et une biopsie de diagnostique en cas d'une azoospermie sécrétoire. La biopsie a été réalisée chirurgicalement après ouverture du scrotum. Le fragment de parenchyme testiculaire prélevé est disséqué à l'aiguille puis centrifugé après gazage ( $6 \% \mathrm{CO} 2$ ? 2 heures) à raison de $400 \mathrm{~g}$ ? 10 $\min$.

Résultats et Discussions : Nous avons réalisés 38 cycles d'ICSI avec biopsie testiculaire. Le taux de fécondation était de $47.23 \%$ par ovocyte mature, ce taux est plus faible que celui obtenu avec du sperme frais $(60 \%)$. Le taux de transfert embryonnaire était faible $(65.8 \%$ vs $90 \%)$. Suite au transfert nous avons obtenu 5 grossesses cliniques soit un taux de grossesse de $13.9 \%$ toujours plus faible que celui obtenu avec du sperme frais $(22.78 \%)$. Le faible résultat biologique de I'ICSI avec biopsie testiculaire est en rapport avec une altération de la qualité des spermatozoïdes, surtout une altération de la maturation spermatique. 
Conclusion : L'optimalisation des résultats de l'ICSI avec biopsie testiculaire repose sur l'amélioration de la qualité du traitement du parenchyme testiculaire in vitro permettant d'optimaliser le $\%$ des spermatozoïdes matures et par conséquence d'augmenter le taux de fécondation, de segmentation et de grossesse.

\section{Références bibliographiques :}

1) Garcia G, Chevallier $D$, Donzeau M, Isnard V et all, Stérilité du couple à définition masculine par azoospermie et fécondation in vitro assistée par micro-injection (F.I.V.-I.C.S.I.) Réflexions à partir d'une étude prospective portant sur nos 42 premiers patients. Progrès en Urologie (2002), 12, 429-436.

2) Izard V, Thiounn N, Poirot C, Bouker A, Epelboin S et all. L'injection intra cytoplasmique de spermatozoïdes (ICSI) dans la prise en charge des azoospermies. Progrès en Urologie (1999), 9, 502-508

3) Flaberty $S P$, Mattews $C D$ : intracytoplasmic sperm injection: instrumentation and injection technique. Reprod Fertil Dev, 1995, 7, 185 96

\section{POSTER 15}

Analyse du statut antioxydant séminal des patients inféconds et sa répercussion sur le bilan biologique de la fécondation in vitro

\section{F. ATIG1, M. AJINA1, M. MERIEM1, S. IBALA1, H. SAIDI1,} A. KERKEN12, A. SAAD1

\section{Unité de Médecine de la Reproduction Hôpital F.Hached Sousse Tunisie \\ ${ }^{2}$ Laboratoire de Biophysique Faculté de Médecine H Bourguiba Monastir atigfatma@hotmail.fr}

Introduction : L'objectif de ce travail consiste à déterminer le statut antioxydant des patients inféconds programmés pour fécondation in vitro et les répercussions de ce statut sur la fécondation ovocytaire et le développement embryonnaire.

Matériel et Méthodes : Notre étude porte sur 57 patients dont six témoins. L'activité enzymatique de la superoxide dismutase (SOD) a été mesurée par la méthode du pyrogallol selon « Marklund et Marklund, (1974) ", celle de la glutathion peroxidase (GPX) a été évaluée par la méthode de « Gunzler et al. 1974» Le dosage du zinc séminal a été fait par la spectrophotométrie d'absorption atomique à flamme. La peroxydation lipidique a été évaluée par la méthode de l'acide thiobarbiturique (TBA).

Résultats et Discussion : Concemant les paramètres séminaux nous avons trouvé que les activités enzymatiques de la SOD et de la GPX ainsi que les concentrations séminales du malondialdéhyde (MDA) sont élevées chez les patients. Nous avons trouvé aussi que l'élément trace «zinc ", le MDA et le GSH sont corrélés avec le taux de fécondation et de segmentation embryonnaire, alors que les antioxydants enzymatiques n'y sont pas. Dans le groupe des patients, le glutathion total (GSH), et le glutathion réduit (GSHr) ont été positivement corrélés avec le taux de fécondation $(P=0,003, P=0,002)$.

Conclusion : En conclusion, les taux élevés de MDA, de SOD et de GPX séminaux confirment l'effet nocif du stress oxydatif sur le sperme et l'infécondité d'origine masculine. La présence des corrélations significatives entre les différentes formes du GSH renforce la contribution paternelle dans le développement embryonnaire précoce.
Références Bibliographiques :

1. Wong W.Y., Hans M.W., Merkus M. et coU. Effects of folic acid and zinc sulfate on male factor subfertility: a double-blind, randomized, placebo-controlled trial. Fertil. Steril. 2002; 77, 3:491-8.

2. Xu D.X., Shen H.M., Zhu Q.X. et coll. The associations among semen quality, oxidative ONA damage in human spermatozoa and concentrations of cadmium, lead and selenium in seminal plasma. Mutat. Res. 2003 ; 534, 1-2: 155-63.

3. Yeung C.H., Cooper T.G., De GeyterM. et cou. Studies on the origin of redox enzymes in seminal plasma and their relationship with resuit cf in-vitro fertilization. Mol. Hum. Reprod.

1998:4: 835-9.

4. Yoshiro S., Takaaki H., Ayako $T$ et coll. Selenoprotein $P$ in human plasma as an extracellular phospholipid hydroperoxide glutathione peroxidase isolation and enzymatic characterisation of human selenoprotein P. J. Biol. Chem. 1999; 274, 5, 2866-71.

\section{POSTER 16}

Le priapisme et devenir de la sexualité : à propos de 26 cas

I. BEN ABDALLAH, M. HADJ SLIMEN, S. KCHAOU, H. KETATA, M.A. MESSEDI, A. SAHNOUN, H. FAKHFAKH, A. BAHLOUL, M.N. MHIRI

\author{
Service d'Urologie, CHU Habib Bourguiba, Sfax, Tunisie \\ kchaou_s@yahoo.fr
}

Objectif : Préciser les aspects étiopathogéniques, thérapeutiques et évolutifs du priapisme à travers une série de 26 cas.

Matériel et Méthodes : Entre 1985 et 2007 nous avons colligé 26 cas de priapisme. Tous les patients ont été pris en charge en urgence avec utilisation de plusieurs modalités thérapeutiques prenant en compte l'étiologie et le délai de consultation. L'évolution a été appréciée par l'examen clinique et l'interrogatoire précisant particulièrement la qualité de la vie sexuelle.

Résultats : L'âge moyen de nos malades a été de 32,5 ans (de 18 mois à 60 ans). Le délai moyen de consultation a été de 4,7 jours. Un facteur étiologique a été retrouvé dans $69,2 \%$ des cas, le priapisme iatrogène médicamenteux était l'étiologie la plus fréquente (50\%). La prise en charge s'est faite sans délai. Nous avons pratiqué une ponction évacuatrice des corps caverneux de première intention chez 7 malades, une anastomose caverno-spongieuse chirurgicale chez 18 malades et une fistule spongio-caverneuse transglandulaire dans 2 cas. Les suites immédiates ont été simples dans tous les cas. L'évolution à distance n'a pu être appréciée que chez 21 malades. Le recul moyen était de 10 mois. Aucun cas de récidive tardive n'a été observé. Une récupération d'une activité sexuelle et/ou d'érections satisfaisantes a été notée dans 9 cas $(42,8 \%)$. Pour le reste des patients, la qualité des érections a été jugée moyenne dans 4 cas et médiocre dans 8 cas (38\%).

Conclusion : Le priapisme est une urgence andrologique dont le traitement s'impose sans délai. Le degré de retentissement sur la sexualité reste important et dépendant de la précocité de prise en charge thérapeutique. 


\section{POSTER 17}

Effects of Date Seed Oil on testicular antioxidant enzymes and epididymal sperm characteristics in male mice

\section{F. BEN ABDALLAHA, I. DAMMAKA, Z. MALLEKC, H. ATTIAA, B. HENTATIA, L. AMMAR-KESKESB}

A Human Pathologies and oxidative stress unit, Superior Institute of Biotechnology of Sfax. Tunisia

$B$ Histo-Embryology Laboratory, Medicine Faculty of Sfax, Tunisia

$C$ Veterinary Research Centre of Sfax, Tunisia fatma_isbs@yahoo.fr

Introduction : Date Seed Oil (DSO) is a natural mixture of antioxidants containing polyphenols and ? tocopherols. The aim of this study was to evaluate the effect of DSO on epididymal sperm characteristics and testicular antioxidants enzymes in male mice.

Materials and Methods : DSO was diluted into isotonic saline solution (0.9\%) and different doses $(5,10,15$ and $20 \%)$ were prepared. Fifty male mice were divided into equal five groups; in four groups DSO was given by intra peritoneal injection of adequate oil solution $(0.3 \mathrm{ml})$, for 28 days daily. The control group was injected by isotonic saline solution without DSO. After period of treatment, animals were sacrificed and body and reproductive organ weights, sperm characteristics (count, motility, viability, and morphology) were assessed. Also, dosage of malondialdehyde (MDA), catalase (CAT) and superoxide dismutase (SOD) activities in testes was performed by spectrophotometric assay.

Results : The body and reproductive organ weight of the control and treated animals did not show any significant changes throughout the course of the investigation. A significant increase in sperm count, motility and viability of all treated animals groups was observed when compared with control group $(P<0.05)$. Unlike, the percentage of abnormal sperm was significantly lower in all treated groups then in control group (Pr0.05). A significant decrease in MDA levels and marked increases in SOD and CAT activities in mice treated with high doses of DSO (15 and 20\%) were also noted.

Conclusion : The present study demonstrated that Date Seed Oil, by means of its natural antioxidant property, can improve the epididymal sperm quality and could ameliorate the testicular strategy defenses in male mice.

\section{POSTER 18}

Résultats de l'AMP chez les hommes blessés médullaires

\section{N. BEN JAMAÄ*, V. SOULA*, D. GOOSSENS*,} H. WALLERAND**, C. HOCKË ${ }^{* \star *}$, A. PAPAXANTHOS-ROCHE*

\footnotetext{
"Service de Biologie de la reproduction-CECOS CHU Pellegrin, Bordeaux, Centre d'Aide Médicale à la Procréation ** Service

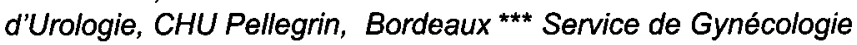
chirurgicale, CHU Saint André, Bordeaux. nadia.ben-jamaa@chu-bordeaux.fr
}

Introduction : La grande majorité des patients blessés médullaires posent un problème de fertilité dû à une anomalie de l'éjaculation secondaire à la lésion médullaire qui peut s'associer à l'altération de la qualité du sperme.
Nous nous proposons d'étudier l'apport des différentes techniques d'AMP dans le traitement de l'infertilité chez les hommes blessés médullaires, quelle que soit la technique adoptée pour le prélèvement du sperme.

Matériels et méthodes : Notre travail consiste à étudier rétrospectivement les résultats de l'AMP de tous les patients blessés médullaires qui ont consulté entre Janvier 1993 et Mars 2008 pour prise en charge de leur infertilité au service de biologie de la reproduction-CECOS du CHU de Bordeaux.

42 patients ont été inclus.

Le choix de la technique a été basé sur la qualité du sperme.

Résultats : L'âge moyen des patients était de $18 \pm 6,13$ ans à l'accident et de $34 \pm 6,23$ à la première tentative d'AMP et celui de leur partenaire de $31 \pm 6.91$ ans à la première tentative.

Le prélèvement de sperme était possible chez 33 patients $(78,6 \%)$, avec ou sans médication (Gutron), par éjaculation spontanée dans 5 cas $(15 \%)$, à l'aide d'un vibromassage dans 21 cas $(46 \%)$ ou une électostimulation anale dans 7 cas $(18 \%)$. Le recours au recueil chirurgical a eu lieu dans 9 cas avec 7 biopsies testiculaires (dont deux étaient négatives) et 2 ponctions épididymo-déférentielles. Le recueil chirurgical des spermatozoïdes n'a été réalisé que lorsque le prélèvement de sperme était impossible ou en présence d'azoospermie.

45 cycles d'inséminations ont été réalisés avec un inséminat moyen de 4.9 millions de spermatozoïdes mobiles et un taux de grossesses par cycle de $17.7 \%$.

Huit cycles de FIV conventionnelle ont été réalisés durant la période d'étude avec un taux de grossesse par cycle de 33.3\%.

Une FIV avec micro-injection (ICSI) a été réalisée dans 77 cycles, soit $24.67 \%$ de grossesse, dont 52 cycles avec du sperme émis, et un taux de grossesses/cycle de $17,3 \% ; 22$ cycles avec sperme testiculaire avec $27,3 \%$ de grossesses/cycle et trois cycles avec spermatozoïdes recueillis par ponction épididymo-déférentielle avec un taux de grossesse de $33.3 \%$ par cycle.

Discussion et conclusion : Notre étude montre des taux de grossesses chez les couples dont l'homme est blessé médullaire, semblables à ceux retrouvés dans notre centre d'AMP, toutes causes d'infertilité masculine confondues.

Les études publiées concernant ce sujet sont peu nombreuses et rapportent des séries de faible effectif.

L'effectif de notre étude, bien que limité, est plus élevé que ceux rapportés dans la littérature, permettant ainsi de mieux définir une stratégie de prise en charge en AMP de ce type de patients.

\section{POSTER 19}

Résultats de I'ICSI chez l'homme infertile en Tunisie : sperme éjaculé versus extraction chirurgicale des spermatozoïdes (TESE)

J. BEN ROMDHANE, G. MERDASSI, A. AYACHI , A.CHAKER, A. FADHALAOUI, S. BEN SLIMA, F. ZHIOUA, A. ZHIOUA, S. MERIAH

Unité de Procréation Médicalement Assistée, Service de gynécologie obstétrique. Hôpital Aziza Othmana. Tunis merdassighaya@yahoo.fr

Introduction : L'Injection intracytoplasmique a constitué une 
révolution dans la prise en charge des infertilités masculines. En effet elle a permis à l'homme infertile de devenir père avec ces propres gamètes qu'il présente une oligoasthénospermie sévére ou même une azoospermie.

Nous rapportons dans ce travail les résultats de l'ICSI d'une étude rétrospective, réalisée au sein du centre de procréation médicalement assistée de l'hôpital Aziza Othmena de Tunis, sur des patients infertiles tunisiens

Matériels et méthodes : L'étude a comporté l'analyse descriptive rétrospective de 107 tentatives d'ICSI avec soit une indication d'oligoasthénotératospermie sévère ou une azoospermie sécrétoire bien définie, cliniquement et histologiquement.

Nous avons exclu de notre étude les mauvaises répondeuses (moins de 4 ovocytes au recueil et $/$ ou $\mathrm{FSH}>=12 \mathrm{UI} / \mathrm{ml}$ ) ainsi que les spermes éjaculés avec une akinésie totale.

La micro-injection a été réalisée à partir de sperme testiculaire frais $(n=56)$ groupe A ou sperme éjaculé $(n=51)$ groupe $B$. Le résultat de ces tentatives en terme de taux de fécondation, d'embryons obtenus et de taux de grossesse par transfert ont été recueillis.

Résultats : L'âge moyen des hommes et des femmes ainsi que le nombre d'ovocytes au recueil étaient homogènes dans les 2 groupes. Le caryotype était normal chez tous les patients ayant une azoospermie sécrétoire.

La biopsie était positive dans $87,5 \%$ des cas.

Dans le groupe Ail y'a une augmentation significative du nombre de 2PN ainsi que le nombre d'embryons obtenus en comparant avec le groupe $B(p<0,05)$.

Le pourcentage de fécondation ainsi que le pourcentage de grossesses cliniques sont augmentés significativement dans le groupe A versus le groupe $B(p<0,05)$.

Conclusion : Nos résultats, ainsi que les données actuelles de la littérature montre que le pourcentage de fécondité ainsi que de grossesses cliniques obtenus avec le sperme éjaculé est significativement supérieur a celui en cas de TESE. Celle-ci reste l'ultime alternative dans les azoospermies non obstructives.

\section{POSTER 20}

\section{Echec d'IIU intraconjugales et devenir en FIV : suivi de cohorte au CHRU de Tours}

M. BLANCHARDA, J. SINGH SANGWANA, F. GUERIFA, C. BARTHÉLÉMYA, M. QUIGNODONA, M.H. SAUSSEREAUA, C. SUIREA, D. ROYEREA

A Service de Médecine et Biologie de la Reproduction, CHRU Bretonneau, 2 Boulevard Tonnelle 37000 Tours, France, Université François Rabelais de Tours, CHRU de Tours, France blanchard@med.univ-tours.fr

Introduction : Chez les patients en situation d'infertilité primaire, même si de nombreux traitements sont disponibles, conseiller le couple dans le choix du traitement adapté est difficile par manque de données consistantes et d'études comparatives poussées. Une étude de cohorte a été menée rétrospectivement pour comparer l'efficacité des IIU puis de la FIV chez les couples en situation d'èchec d'IIU par rapport à deux populations témoins de FIV-D et de FIV tubaires.
Matériel et méthodes : La cohorte comprenait 472 couples au départ initiant des IIU, 171 ont poursuivi par des tentatives de FIV (FIV classique pour la première ponction) suite aux échecs des IIU. La population témoin de FIV-D comporte 205 couples et celle de FIV tubaire 397 couples. La sortie de cohorte pour chaque couple correspondait soit à une naissance vivante soit à un abandon.

Résultats : En IIU, le taux de naissance par cycle est de $11,4 \%$, le taux de naissance cumulée au sixième cycle est de $34,1 \%$ et le taux d'abandons de $29,7 \%$. En FIV après échec d'llU, le taux de naissance par cycle est de $23,1 \%$, le taux de naissance cumulée à la quatrième tentative (TEC compris) de $48,5 \%$ et le taux d'abandons de $42,7 \%$.

Discussion et conclusion : L'âge de la femme est le principal facteur prédictif de l'issue des inséminations et des FIV. Les résultats obtenus en FIV sont globalement similaires à ceux obtenus dans les populations témoins. Néanmoins le taux d'abandons en FIV est plus faible et le taux d'échecs de fécondation est légèrement plus élevé dans la population étudiée par rapport aux deux groupes de référence. Finalement $51,7 \%$ des couples ont réalisé leur projet parental principalement en IIU même si le taux de naissance cumulée est plus élevé en FIV; $45,1 \%$ des couples ont abandonné en cours de prise en charge - le taux d'abandons étant plus élevé en FIV qu'en IIU et $3,2 \%$ des couples se sont retrouvés en situation d'échec après toutes les tentatives. En introduisant la notion de coût-efficacité dans la discussion, on constate comme précédemment décrit dans la littérature que les IIU apportent un bénéfice plus intéressant, pourvu que l'indication et le nombre de cycles soient adaptés à chaque couple pris en charge en Assistance Médicale à la Procréation.

\section{POSTER 21}

L'azoospermie non obstructive : un score prédictif de l'extraction de spermatozoïdes testiculaires ?

\section{F. BOITRELLE1, G. ROBIN2, F. MARCELLI2, C. MARCHETTI3, B. LEROY-MARTIN3, J.-C. HERBAUT4, P. PIGNY5, J.M.} RIGOT3,6, V. MITCHELL16

1 Laboratoire de Spermiologie CHRU Lille, 2 Service d'Andrologie CHRU Lille, 3 Laboratoire de Biologie de la Reproduction CHRU Lille, 4 Laboratoire Biolille, 5 Laboratoire d'Endocrinologie CHRU Lille, 6 EA 4308 Universités Rouen et Lille 2. E-mail : florenceboitrelle@yahoo.fr

Introduction : Chez l'homme azoosperme, l'extraction chirurgicale de spermatozoïdes suivie d'ICSI est la seule chance d'envisager une paternité. Fructueuse dans $90 \%$ des cas chez les patients présentant une azoospermie obstructive, l'extraction n'est positive qu'une fois sur deux dans l'azoospermie non obstructive (ANO). Actuellement, aucun élément clinique ou paraclinique ne serait, à lui seul, prédictif du prélèvement de spermatozoïdes testiculaires dans l'ANO. Le but de cette étude est d'évaluer la valeur prédictive d'un score dans l'extraction de spermatozoïdes testiculaires chez les patients ANO.

Méthodes : Dans notre centre, 280 patients ANO ont été opérés entre 2002 et 2008 . Pour chaque patient, nous avons calculé un score dont la formule combine 3 paramètres non invasifs déterminés en préopératoire : les dosages sériques de FSH et d'Inhibine B, et le volume testiculaire total échographique.

Résultats : Le taux d'extraction positive de spermatozoïdes testiculaires est de $53,2 \%$. Le score est inférieur à 18,5 pour $102 / 280$ patients $(36,4 \%)$ et supérieur pour $178 / 280$ patients $(63,6 \%)$. Si le score est inférieur à 18,5 , les chances d'extraction de spermatozoïdes sont de $77,4 \%$. Dans $10,1 \%$ des cas, les spermatozoïdes extraits 
sont très rares. Au delà de 18,5, les chances d'extraction sont de $39,3 \%$ et les spermatozoïdes sont très rares dans $44,3 \%$ des cas. Chez les patients dont le score est supérieur à $270(n=37)$, les chances d'extraction sont de $37,8 \%$ et les spermatozoïdes sont très rares dans $71,4 \%$ des cas.

Discussion et conclusion : Chez le patient ANO, ce score aurait une bonne valeur prédictive du succès d'extraction chirurgicale de spermatozoïdes. De plus, il pourrait renseigner sur la qualité de l'extraction et se révéler utile pour optimiser la prise en charge des patients à risque d'extraction pauvre en spermatozoïdes testiculaires. Il contribuerait alors à améliorer le pronostic de l'infertilité de l'homme azoosperme.

Travaux financés par le PHRC 2004 R-1908, Evaluation de nouveaux marqueurs biologiques dans la prise en charge des patients azoospermes, et par la coopération régionale G4 Reproduction.

\section{POSTER 22}

Vers une identification des mécanismes à l'origine des aneuploïdies spermatiques chez les patients azoospermes à caryotype normal

\author{
H. BOUAZZI1, M. BAILLY1,2, I. HAMMOUD1,2, J.C. PONT1, \\ D. MOLINA-GOMES1,2, M. ALBERT1,2, R. WAINER1,2, J. \\ SELVA1, 2, F. VIALARD1,2 \\ 1 : Laboratoire d'Histologie, Embryologie, Biologie de la \\ Reproduction, Cytogénétique et Génétique médicale, CHI Poissy \\ St Germain, 78303 Poissy Cedex. \\ 2 : EA 2493, UVSQ, 78000 Versailles \\ fvialard@hotmail.com
}

Introduction : Chez les patients ayant une azoospermie non obstructive et un caryotype normal, la biopsie testiculaire permet dans certains cas de retrouver des spermatozoïdes utilisables ultérieurement en ICSI. Néanmoins, ces spermatozoïdes présentent une augmentation du taux d'aneuploïdie par rapport à ceux de sujets témoins, à sperme normal selon les critères de l'OMS. Cette augmentation des anomalies gamétiques pourrait être due, soit à l'entrée en méiose de spermatogonies anormales, soit à une augmentation des anomalies méiotiques, éventuellement liée à un micro-environnement testiculaire délétère et commun à d'autres étiologies non chromosomiques d'altération de la spermatogenèse. Afin de répondre à cette question, nous avons voulu comparer les anomalies méiotiques chez des patients présentant une azoospermie sécrétoire à caryotype normal, et chez des patients à spermatogenèse normale.

Matériel et Méthodes : 3 groupes de patients ont été inclus : Gpe $1: 19$ patients à caryotype normal ayant une azoospermie non obstructive confirmée par l'étude histologique ; Gpe 2 :36 patients ayant une azoospermie obstructive et une spermatogenèse normale confirmée par l'ètude histologique (14 avec agénésie bilatérale des canaux déférents $(A B C D)$ et une altération du gène CFTR, 11 avec une étiologie infectieuse ou inflammatoire, 11 ayant des étiologies variées) ; Gpe 3 : 11 patients contrôles avec des caractéristiques spermatiques normales selon les critères de l'OMS. Le stade pachytène et les cellules post méiotiques ont été étudiés dans les groupes 1 et 2, et les spermatozoïdes pour le groupe 3, en utilisant les sondes centromèriques des chromosomes $X, Y$ et 18.

Résultats : Les taux d'aneuploïdies spermatiques sont augmentés $(p<0.0001)$ dans le groupe $1,4.0 \%(n=2848)$, comparés à ceux des groupes 2 et 3 avec respectivement $0.7 \%(n=25400)$ et $0.6 \%$ $(n=11178)$. Il en est de même au stade des spermatides. Ces anomalies touchent aussi bien les gonosomes que le chromosome 18 , que la 1 ère et la $2^{\text {ème }}$ division méiotique. Parmi les patients ayant une azoospermie obstructive, les $A B C D$ semblent avoir un taux d'aneuploïdies spermatiques $(0.9 \%, p<0.05)$ supérieur par rapport aux patients témoins. Aucun pachytène aneuploïde n'a été observé, par contre une augmentation significative des désappariements des gonosomes a été retrouvée chez les patients ayant une azoospermie non obstructive $(14.0 \%, n=630, p<0.0001)$ et chez les $A B C D(5.6 \%$, $n=1130, p<0.05$ ) par rapport aux autres patients ayant une azoospermie obstructive $(4.0 \%, n=3152)$.

Conclusion : Dans cette série, tous les spermatozoïdes sont issus de pachytène euploides, que le patient ait une azoospermie obstructive ou non. Ceci est en faveur d'anomalies survenues durant la méiose chez les patients ayant une azoospermie non obstructive à caryotype normal. Ces anomalies surviennent durant les 2 divisions méiotiques et touchent tous les chromosomes. Ceci pourrait être dû à un effet délétère de l'environnement testiculaire, comme le suggère le taux de désappariement des gonosomes chez les patients ayant une azoospermie non obstructive. Enfin, les résultats obtenus chez les patients à $A B C D$ devront être confirmés sur une plus grande série.

\section{POSTER 23}

Impairment of spermatogenesis in rats by merchuric chloride : Involvement of low 17ß-estradiol in induction of acute oxidative stress

\section{M.A. BOUJBIHA, K. HAMDEN \& A. EL FEKI}

boujbiha_medall@yahoo.fr

Mercuric chloride (MC) has been shown to affect the male reproductive organs. However, the specific mode of impairment of spermatogenesis during MC-exposure has not yet been clarified fully. In this study, we attempted to characterize the mechanism by which MC, a toxic metal, exerts adverse effects on testicular steroidogenic and gametogenic activities in association with testicular oxidative stress (OS) in rats. MC-treatment at 50 and $100 \mathrm{ppm}$ for 90 days by continuous oral administration in the drink water resulted in significantdose dependent-fashion diminution in testicular 17ß-estradiol $\left(E_{2}\right)$ levels, without statistical alteration in testosterone level among MCexposed groups compared to the control. Cauda epididymal sperm count and motility were decreased significantly $(p<0.01)$, in a dose dependent manner among the MC-treated groups, and qualitative examination showed that MC at the concentrations employed produced histological alterations which were prominent with highest dose. Thus, MC might partially suppress spermatogenesis. When compared to the control, OS induced by MC-treatment substantially increases lipid peroxidation (LPO) levels with corresponding decrease $(p<0.01)$ in the activities of antioxidants enzymes superoxide dismutase (SOD) and catalase (CAT) in testis. Unless, OS can lead to cancer development, testis's tumor markers as Beta Human Chorionic Gonadotropin (b-hCG) and Alpha-foetoprotein (AFP) levels has shown no significant differences in the MC-exposed group compared with respect to the control. Large quantities of metal accumulated in the testis tissue are in agreement with the testis-activity failure verified in this tissue. With regard to the antioxidant properties of $E_{2}$, as a paracrine effector in testis, our results suggest that Mcinduced hypospermatogenesis was a mix of ROS and reduction in enzyme scavenger's activities as a consequence of $E_{2}$ level decrease. 


\section{POSTER 24}

Interêt des lunettes-loupes dans les prélèvements épididymotesticulaires pour ICSI, à propos d'une série de 474 prélèvements pratiqués par le même opérateur et revue de la littérature

\section{A. BQUKER, L. HALOUANI, M. KHAROUF, H. LATROUS, M. MAKNI, O. MARRAKCHI, R. ZOUARI \\ Clinique Taoufik, 1002 Mutuelleville, Tunis, Tunisie aminbouker@gmail.com}

Introduction : Les protocoles de stimulation ovarienne, les ponctions ovocytaires, la culture et le replacement embryonnaire ont fait l'objet de nombreuses améliorations techniques ; seul les prélèvements de spermatozoïdes continuent à être pratiqués à l'oeil nu par une très grande majorité d'urologues alors que l'usage des lunettes-loupes ou du microscope a été décrit il y a bientôt dix ans.

On se propose donc de décrire la technique de prélèvement sous lunettes-loupes en s'aidant de nombreuses diapositives peropératoires.

Matériel et méthodes : II s'agit d'une étude rétrospective où 474 dossiers sont colligés. Sont notés les territoires biopsiés et la corrélation entre aspect macroscopique (tubes séminifères dilatés ou pas) et analyse biologique.

Résultats : Le nombre et la positivité des biopsies sont exprimés en fonction de chaque type histologique.

Discussion : La technique opéraoire est précisée et son interêt est confirmé par la revue de la littérature. Les prélèvements dirigés permettent de préserver la pulpe testiculaire tout en limitant le travail des biologistes. L'usage des loupes trouve également son utilité dans le repérage et l'ablation des petites tumeurs qui ne sont pas rares dans l'azoospermie sécrétoire.

Conclusion : L'usage des lunettes-loupes permet de repérer les tubes séminifères dilatés et de pratiquer de petits prélèvements dirigés plutôt que de prélever au hasard de volumineux fragments de pulpe testiculaire.

\section{POSTER 25}

Amputation du gland après circoncision : à propos de 8 cas

\author{
K. CHABCHOUB, M. FOURATI, A. SAHNOUN, \\ S. HADJ, H. FAKHFAKH, A. BAHLOUL, M.N. MHIRI \\ Service Urologie CHU H Bourguiba Sfax Tunisie \\ k.chabchoub@laposte.net
}

Introduction : Sous nos climats, la circoncision reste l'intervention la plus couramment pratiquée chez le garçon. Elle est souvent réalisée par un personnel paramédical non qualifié, ou même en dehors du milieu médical dont les notions de chirurgie et d'asepsie sont aléatoires. Elle est réputée comme chirurgie bénigne mais des complications majeures parfois très graves engageant le pronostic sexuel voir vital, peuvent survenir.

Patients et méthodes : Nous rapportons 8 cas d'amputation du gland suite à une circoncision en milieu extra hospitalier selon les méthodes traditionnelles.
Résultats : L'âge moyen des enfants est de 6 ans ( 3 à 8 ans). L'amputation du gland était faite lors de la circoncision dans 4 cas dont deux avec section complète. Dans les autres cas, il s'agissait d'une nécrose du gland à cause d'un arc électrique lors de l'utilisation inadéquate du bistouri électrique. Une reconstruction urgente du gland n'avait pu être réalisable que dans 3 cas. Le gland sectionné dans le 4ème cas était de mauvaise qualité. On n'a noté qu'un seul succès de revascularisation du gland.

Le délai de consultation en cas de nécrose du gland était de 3 jours en moyenne. Le traitement n'avait consisté qu'en la réalisation d'une méatoplastie pour obtenir un méat urétral satisfaisant avec réfection de la peau pénienne.

Discussion et conclusion : La section du gland demeure une complication certes rare de la circoncision mais très grave engageant le pronostic sexuel ultérieur de l'enfant. Ceci rend cette intervention non anodine et doit inciter à ne la réaliser qu'en milieu spécialisé par un personnel compétant.

\section{Références bibliographiques :}

1. A. ESSID, M. HAMZAOUI, S. SAHLI, T. HOUISSA : Réimplantation balanique après accident de circoncision. Prog Urol (2005), 15, 745747.

2. ATIKELER M.K., ONUR R., GECIT l., SENOL F.A., COBANOGLUB. : Increased morbidity after circumcision from a hidden complication. B.J.U. Int., $2001 ; 88: 938-940$.

3. SYLLA C., DIAO B., DIALLO A.B., FALL P.A., SANKALE A.A., BAM., Les complications de la circoncision. A propos de 63 cas. Prog. Urol., 2003, 13, 266-272

\section{POSTER 26}

Sexualité après dérivation urinaire externe continente de type Mitrofanoff

\section{K. CHABCHOUB, A. MSSEDDI, M. FOURATI, H. FAKHFAKH, A. BAHLOUL, M.N. MHIRI \\ Service Urologie CHU HABIB BOURGUIBA - SFAX, TUNISIE k.chabchoub@laposte.net}

Introduction : Nombreux patients porteurs d'une dérivation urinaire de type MITROFANOFF sont jeunes. Ils doivent néanmoins prétendre à une vie et un avenir sexuel les plus équilibrés possibles. On se propose d'étudier la sexualité de tels patients en précisant surtout les facteurs qui risquent de l'entraver.

Matériel et méthodes : Vingt hommes et 5 femmes porteurs d'une dérivation urinaire de type Mitrofanoff ont été questionnés à propos de leur sexualité. Leurs dérivations urinaires externes de type Mitrofanoff ont été réalisées entre 1992 et 2005 . L'âge moyen est de 29 ans ( 25 - 67 ans). Une vessie neurologique pathologique a été l'indication majeure de leur dérivation urinaire. Cinq femmes et 6 hommes sont mariés. Deux mariages (1 homme et 1 femme) ont eu lieu 7 ans après la réalisation de la dérivation. Le reste des hommes sont célibataires. Un questionnaire leur a été dédié concermant la qualité de vie quotidienne; sociale, familiale et sexuelle.

Résultats : Le recul moyen est de 36 mois ( 3 ans) (6 à 192 mois). La vie sexuelle des couples s'est nettement rééquilibrée après disparition des troubles du bas appareil urinaire dont surtout l'incontinence d'urine. Le désir sexuel et l'orgasme ont été le mieux ressentis avec satisfaction de leurs partenaires. Toutefois, 4 hommes célibataires ont signalé un déséquilibre sexuel persistant consécutif à leurs pathologies originelles; myélite vasculaire (1 cas), complications dégénératives du diabète $(3$ cas). Vingt et un patients 
(84\%) ont exprimé une satisfaction manifeste en post opératoire pour des raisons hygiéniques et ne ressentent aucune contrainte psychologique ni d'atteinte de l'intégrité de leurs images corporelles.

Discussion et Conclusion : La disparition des troubles du bas appareil urinaire et la sensation de l'intégrité de l'image corporelle sont des facteurs déterminant pour une réadaptation sexuelle satisfaisante pour des patients jeunes et motivés après la réalisation d'une dérivation urinaire externe continente de type Mitrofanoff.

\section{POSTER 27}

Evaluation des spermatozoïdes porteurs d'importantes vacuoles des têtes spermatiques à l'aide d'un marqueur de l'acrosome et de la fragmentation de l'ADN spermatique

\section{M.H. CHELLLI, E. GRUEL, S. MASURIER, A. PERDRIX, N. MOUSSET-SIMÉON, B. MACE, N. RIVES}

Laboratoire de Biologie de la Reproduction-CECOS, EA 4308 "Spermatogénèse et Qualité du gamète mâle", CHU Hôpitaux de Rouen,76031Rouen nathalie.rives@chu-rouen.fr

Introduction : Depuis les cinq dernières années, l'IMSI (Intracytoplasmic Morphologically selected Sperm Injection) connaît un réel engouement dans les laboratoires de biologie de la reproduction, malgré son surcoût. Souvent controversés, les avantages qui lui sont attribués sont un meilleur taux d'implantation, de grossesse, d'accouchement ainsi qu'une diminution des taux des fausses couches spontanées. II reste que cet outil se révèle très intéressant pour l'étude de la morphologie fine spermatique, ce qui permet par la suite d'effectuer des tests spécifiques sur une catégorie de population spermatique morphologiquement définie et sélectionnée. Ainsi, la morphologie spermatique observée en IMSI évoque un questionnement récurrent chez tous les utilisateurs : de quelle nature sont les vacuoles observées sur la tête spermatique?

En partant du principe que l'origine de ses vacuoles soit acrosomique ou nucléaire, nous avons tenté de répondre à cette question en travaillant sur la population spermatique présentant le plus grand nombre et la plus grande surface de vacuoles visibles au grossissement $\times 6600$ utilisé en IMSI.

Matériel et Méthodes : Nous avons pour cela effectué un tri sélectif des spermatozoïdes de type 3 selon la classification établie dans notre laboratoire (au moins une vacuole dont le rapport surface vacuolaire/surface de la tête spermatique est strictement supérieur à $13 \%$ ) chez 10 patients venus consulter dans notre centre pour infertilité. Ce tri a été possible grâce à un microscope inversé LEICA (France) équipé de l'objectif $\times 1000$ pour l'IMSI ainsi que d'un logiciel de calcul des surfaces. Les spermatozoïdes recueillis étaient ensuite fixés sur lame et analysés par deux techniques couplées : marquage de la pro-acrosine à l'aide de l'anticorps monoclonal Mab 4D4 associée à l'étude de la fragmentation de l'ADN spermatique par la technique TUNEL Roche Molecular Biology, France). Notre hypothèse était qu'une anomalie du marquage de la pro-acrosine serait le témoin de la présence de vacuoles acrosomiques et que le marquage positif en TUNEL serait le témoin de l'origine nucléaire des vacuoles.

Résultats : Un total de 250 spermatozoïdes a été analysé chez nos 10 patients. $77 \%$ des acrosomes étaient anormaux, $23 \%$ des acrosomes anormaux étaient en fait des acrosomes absents. La recherche d'ADN fragmenté par TUNEL n'a montré aucun spermatozoïde à ADN entièrement fragmenté chez tous les patients. Néanmoins, certaines images laissent entrevoir des sites d'initiation de fragmentation de l'ADN ( $29 \%$ en moyenne de la totalité des spermatozoïdes analysés).

Discussion et Conclusion : D'après notre étude, ce qui paraît surprenant est qu'un spermatozoïde de type 3 ne présente pas obligatoirement d'acrosomes malformés ou d'altération de l'ADN nucléaire ; mais les vacuoles acrosomiques semblent les plus fréquentes dans ce type morphologique. La présence d'un marquage localisé au TUNEL sur certains de ces spermatozoïdes nous laisse supposer que l'altération de l'ADN nucléaire spermatique peut entraîner des modifications morphologiques visibles au grossissement de l'IMSI. L'amélioration sensible des résultats en IMSI par la sélection et l'injection de spermatozoïdes les plus parfaits possibles serait due selon notre étude à l'élimination des spermatozoïdes en début de fragmentation de l'ADN spermatique.

\section{POSTER 28}

Effet du traitement de la leucospermie sur les paramètres du spermogramme

\section{FEKIH, A. JNIFENE, S. KEBAILI, S. HIDAR, L. BEN REGAYA, M. BIBI, H. KHAIRI}

Service de Gynécologie obstétrique et de Médecine de reproduction CHU Farhat Hached, Sousse kebaili.sahbi@yahoo.fr

Introduction : La leucospermie entraine un stress oxydatif avec libération de radicaux libres responsables d'altération de la qualité des spermatozoïdes.

L'objectif de notre étude est d'évaluer l'effet du traitement de la leucospermie sur les paramètres du spermogramme.

Patients et méthodes : Etude rétrospective colligeant 30 patients avec au spermogramme une leucospermie (> 1 million selon OMS). Les différentes caractéristiques du sperme avant et après traitement par antioxydant et antibiotique ont été analysées.

Résultats : L'âge moyen de nos patients est de 35 ans. Un antécédent de chirurgie testiculaire retrouvé dans un seul cas. Le bilan de stérilité féminine est normal dans tous les cas. L'examen a révélé l'existence d'une varicocèle dans 4 cas. La spermoculture est positive dans $26 \%$ des cas. Un traitement antibiotique a été indiqué dans $100 \%$ des cas et antioxydant dans $56 \%$ des cas. Une oligospermie a été retrouvé dans $50 \%$ des cas et seulement dans $24 \%$ des cas après traitement. Une asthenospermie a été retrouvé dans tous les cas et a persisté après traitement dans $66 \%$ des cas. Une teratospermie notée dans $70 \%$ des cas a persisté dans $44 \%$ des cas après traitement.

Conclusion : II semble que le traitement antioxydant et antibiotique améliore la qualité des spermatozoïdes. Certaines équipes discutent même l'intérêt de substitution des milieux des cultures par un antioxydant améliorant ainsi les chances de grossesse. 


\section{POSTER 29}

Effet du traitement de la leucospermie sur les résultats d'ICSI

\section{FEKIH, A. JNIFENE, S. KEBAILI, S. HIDAR, L. BEN REGAYA, M. BIBI, H. KHAIRI}

Service de Gynécologie obstétrique et de Médecine de reproduction CHU Farhat Hached, Sousse kebaili.sahbi@yahoo.fr

Introduction : L'infection génitale est une cause fréquente de stérilité masculine $(11 \%$ des cas). Les mécanismes physiopathologiques incriminent un stress oxydatif avec libération de radicaux libres responsables d'altération de la qualité des spermatozoïdes.

L'objectif de notre étude d'èvaluer l'intérêt de traitement de la leucospermie en terme de résultats d'ICSI.

Patients et Méthodes : Etude rétrospective colligeant 30 patients avec au spermogramme une leucospermie (> 1 million selon OMS). Les différentes caractéristiques du sperme avant et après traitement du sperme ont été analysées. La qualité embryonnaire, le nombre d'embryons transférés, le taux de segmentation et le taux de grossesse ont été étudies.

Résultats : L'âge moyen de nos patients est de 35 ans. II s'agit d'une stérilité primaire dans $86 \%$ des cas et secondaire dans $14 \%$ des cas. Un antécédent de chirurgie testiculaire retrouvé dans un seul cas. Le bilan de stérilité féminine est normal dans tous les cas. L'examen a révélé l'existence d'une varicocèle dans 4 cas. La spermoculture est positive dans $26 \%$ des cas. Un traitement antibiotique a été indiqué dans $100 \%$ des cas et antioxydant dans $56 \%$ des cas. Les embryons obtenus sont de type I dans $66 \%$ des cas. Le taux de grossesse après traitement de la leucospermie est de $29 \%$.

Conclusion : Il semble que le traitement de la leucospermie améliore les résultats d'ICSI en termes de taux de grossesse. Certaines études discutent même l'intérêt de substitution d'antibiotiques et d'antioxydants dans les milieux de culture.

\section{POSTER 30}

Hypertrophie bénigne de la prostate et sexualité

\section{FOURATI, A. SAHNOUN, M.A. MSEDDI, M. HADJSLIMEN, H. KETATA, A. BAHLOUL, M.N. MHIRI \\ Service d'urologie CHU Habib Bourguiba. Sfax. Tunisie. Fourati.mohamed@yahoo.fr}

Introduction : L'hypertrophie bénigne de la prostate (HBP), constitue une pathologie fréquente de l'homme. Elle peut retentir sur la qualité de vie et parfois la sexualité des patients. Notre but est d'évaluer les conséquences sexuelles de l'hypertrophie bénigne de la prostate.

Matériel et Méthodes : Notre étude a été prospective entamée au début du mois de mars 2008 jusqu'à juillet 2008 . Les troubles urinaires du bas appareil et la fonction sexuelle ont été évalués par des questionnaires validés, y compris l'échelle IPSS (Score international de symptôme prostatique), l'èchelle DAN-PSS (Score de symptôme prostatique danois) et l'indice IIEF (Indice international de la fonction érectile).

Ces questionnaires ont été posés à 18 patients entre 50 à 80 ans.
Tous les patients avaient une indication opératoire de leur adénome.

Résultats : L'âge moyen de nos patients était de 66 ans. Quatre patients étaient diabétiques équilibrés, 8 patients étaient hypertendus et deux patients étaient coronariens. Les patients étaient classés en fonction de la sévérité de leur symptomatologie : $33 \%$ avait une symptomatologie modérée et $66 \%$ sévère. Le retentissement sur la qualité de vie était partagé de façon équivalente entre moyenne et mauvaise.

Sur le plan sexuel, tous les hommes avaient une activité sexuelle habituelle durant les 4 dernières semaines. Les rapports étaient espacés dans $77 \%$ des cas, une dysfonction érectile dans $27 \%$ des cas à type de trouble de l'érection ou de la pénétration et un trouble de l'éjaculation dans $22 \%$ des cas, qui correspondait respectivement à $100 \%, 41 \%$ et $25 \%$ des patients qui avaient une symptomatologie sévère.

Conclusion : L'altération de la sexualité fonctionnelle était corrélée à la sévérité des symptômes chez les patients d'où l'importance clinique de l'évaluation des TUBA chez les patients atteints de dysfonction sexuelle, et la nécessité de prendre en compte les aspects sexuels lors de la prise en charge des patients présentant une hypertrophie bénigne de la prostate.

\section{POSTER 31}

Les tumeurs germinales du testicule : à propos de 35 cas

\section{FOURATI A. SAHNOUN, M.A. MSEDDI, M. HADJSLIMEN, H. KETATA, H. FAKHFAKH, A. BAHLOUL, M.N. MHIRI \\ Service d'urologie CHU Habib Bourguiba. Sfax. Tunisie Fouratimohamed@yahoo.fr}

Introduction : Le cancer du testicule est rare et survient essentiellement chez l'homme jeune. Les tumeurs germinales représentent le type le plus fréquent. On se propose d'étudier les aspects épidémiologiques, diagnostiques, thérapeutiques et pronostiques de cette pathologie.

Matériel et méthodes : Etude rétrospective de 35 cas de tumeurs germinales du testicule colligés sur une période de 24 ans (1984 à 2007). Nous avons répartis nos patients en 2 groupes : $\mathrm{Gr} 1$ (13 cas de tumeurs séminomateuses soit $37 \%$ ), Gr 2 (22 cas de tumeurs non séminomateuses soit $63 \%$ ).

\section{Résultats :}

Groupe 1: L'âge moyen était de 40 ans. Le diagnostic était révélé par une grosse bourse ( 7 cas), un abdomen aigu (3 cas) et autres ( 3 cas). Le bilan d'extension montrait des adénopathies (ADNP) dans 5 cas. L'examen anatomopathologique trouvait un séminome typique dans tous les cas. Les malades ont été classés en stade 1 ( 7 cas), stade $2 \mathrm{a}$ ( 2 cas), stade $2 \mathrm{~b}$ ( 2 cas) et stade $2 \mathrm{c}$ ( 2 cas). Un traitement complémentaire était nécessaire : radiothérapie lomboiliaque (10 cas), chimiothérapie (3 cas) et chirurgie de masse résiduelle ( 1 cas). Après un recul moyen de 6 ans 5 mois (1-16 ans), tous nos patients étaient en rémission complète.

Groupe 2 : L'âge moyen était de 30 ans. Le diagnostic était révélé par une grosse bourse ( 19 cas dont 4 dans un contexte aigu), des métastases viscérales (5 cas). Les ?FP étaient élevés chez 12 patients alors que le taux des BHCG était élevé chez 6 patients. L'examen anatomopathologique trouvait un carcinome embryonnaire pur ( 7 cas), un tératome immature ( 1 cas), des tumeurs mixtes avec carcinome embryonnaire majoritaire ( 9 cas) et avec choriocarcinome 
majoritaire (5 cas). Dix cas ont été classés en stade 1. Parmis eux, 7 avaient eu une chimiothérapie adjuvante et 3 ont été surveillés ; leur survie à 5 ans était de $100 \%$. Trois patients classés en stade 2c (N3), ont été traités par une chimiothérapie adjuvante et étaient tous décédés après un recul moyen de 3 mois. Parmis les 9 patients classés stade $4(\mathrm{M}+), 3$ étaient décédés avant de débuter la chimiothérapie; les 6 patients restants avaient reçu une chimiothérapie de type BEP : 4 étaient décédés dans les suites de la chimiothérapie et 2 étaient en rémission complète après une chimiothérapie de 2ème ligne (VeIP) et une exérèse des masses résiduelles.

Conclusion : Le pronostic des tumeurs germinales du testicule est amélioré par l'association à la chirurgie des nouveaux protocoles de radio et de chimiothérapie. Toutefois, ces tumeurs restent toujours un objet constant de recherche puisqu'elles représentent un modèle de curabilité par une approche multidisciplinaire.

\section{POSTER 32}

Impact du cadmium sur la spermatogenèse in vitro

\section{R. GHALAMOUN-SLAIMlab, C. GEOFFROY-SIRAUDINb, A. BOTTAb, P. DURANDc, K. MEBAREKa, M. GUICHAOUAb}

\author{
a Service d'histologie-Embryologie, Faculté de Médecine d'Oran, \\ Université d'Oran, Algérie \\ b Laboratoire de Biogénotoxicologie et Mutagenèse \\ Environnementale (EA1784), Aix-Marseille Université, Fédération \\ de Recherche 3098, ECCOREV, Marseille, France \\ c Unité INSERMIINRA U418, Institut de Génomique Fonctionnelle \\ de Lyon, UMR 5242, Ecole Normale Supérieure de Lyon, France \\ ghalamoun_rahma@yahoo.fr
}

Introduction : Le cadmium est un métal lourd dont les principaux minéraux sont l'oxyde, le chlorure, le bromure, le nitrate, le sulfure et le Séléniure de cadmium. Tous ces composés ont un effet génotoxique. Les principales sources de cadmium sont : le tabac qui est la principales source de contamination, l'alimentation (poissons, crustacés) et les sources industrielles. Le cadmium est aussi présent dans l'air, dans la fumée et les poussières perdues par certaines industries. Il pénètre principalement dans l'organisme par voie respiratoire, accessoirement par voie digestive. Outre ses effets toxiques et cancérigènes, le cadmium est responsable d'une altération de la spermatogenèse se manifestant par une oligoasthénozoospermie. Il a en particulier un effet inducteur de l'apoptose sur les cellules germinales.

Matériel et Méthodes : Nous avons développé en collaboration avec l'équipe INSERM/INRA U418 à Lyon, un modèle d'étude in vitro de la méiose de rat afin de pouvoir étudier les effets des toxiques sur la différenciation des cellules germinales. Notre travail a été d'établir le profil de différenciation des cellules germinales et d'analyser les anomalies des complexes synaptonémaux (CS) in vitro, dans des cultures de tubes séminifères de rat de 23 jours, une culture témoin sans cadmium, et trois cultures dans lesquelles ont été introduites des concentrations croissantes de cadmium, $0.1 \mu \mathrm{g}, 1 \mu \mathrm{g}$ et $10 \mu \mathrm{g} / \mathrm{ml}$. Pour chaque prélèvement ont été faits aux jours $5,7,9,12,14$ et 16. Nous avons utilisé la technique d'immunocytochimie en fluorescence avec l'anticorps anti-SCP3 qui révèle les quatre premiers stades de la prophase I de la méiose.

Résultats : Nous avons montré que le cadmium n'altérait pas la chronologie de la méiose, mais qu'il provoquait, de façon dose dépendante, une perte cellulaire importante et faisait apparaître des lésions sévères des CS. L'anomalie la plus fréquemment rencontrée était l'altération de la structure des CS, leur donnant un aspect «mité», associé à des défauts d'appariements. Cette anomalie n'a jusqu'à présent jamais été décrite Les autre anomalies observées étaient la fragmentation des CS, les asynapsis et les bivalents en pointillés.

Discussion et conclusion : Nos résultats mettent en évidence l'effet toxique du cadmium sur les cellules méiotiques du rat. Des tests de génotoxicité sont en cours de développement afin d'étudier le risque pour le contenu génétique des gamètes d'une contamination par métal. Ce travail met aussi l'accent sur l'intérêt de ce modèle de culture de cellules germinales dans l'étude de l'effet des reprotoxiques environnementaux.

\section{POSTER 33}

Effets de la tératozoospermie sur la mobilité des spermatozoïdes

\section{N. GUEDICHE, S. IBALA, M. MEHDI, M. AJINA, A. SAAD}

Service de Cytogénétique et de Biologie de la reproduction, Hôpital Farhat Hached, Sousse, Tunisie narjesg@yahoo.fr

Introduction et objectifs : L'analyse de la mobilité spermatique est un des moments forts du spermogramme puisqu'il explore les capacités cinétiques des spermatozoïdes à atteindre le site de la fécondation. L'objectif de ce travail est d'évaluer l'effet des perturbations morphologiques des spermatozoïdes sur leur capacité à se mouvoir et de mettre en évidence les anomalies les plus influentes sur la qualité du mouvement spermatique.

Matériel et Méthodes : Nous avons analysé le sperme de 1742 patients ayant consulté pour infertilité du couple au laboratoire de Cytogénétique et de Biologie de la reproduction de l'Hôpital « Farhat Hached " de Sousse entre 2002 et 2007 . Les données concernant l'âge des patients, l'origine géographique, le type et la durée de l'infertilité ont été recueillies par l'interrogatoire.

Le volume de l'éjaculat, la viscosité, le $\mathrm{pH}$, la numération, la présence de leucocytes, la mobilité, la vitalité et la morphologie des spermatozoïdes ont été évalués selon les normes de l'OMS. Afin d'éviter tout biais dans les résultats, nous avons sélectionné uniquement les patients qui avaient un sperme de viscosité normale avec un pH entre 7,2 et 8 , une nécrozoospermie inférieure à $25 \%$ et un taux de leucocytes inférieur à $1 \mathrm{million} / \mathrm{ml}$.

Résultats : Sur les 1742 patients, $25,5 \%$ ont une mobilité totale 30 minutes après l'éjaculation normale ( $>50 \%$ ), et $74,5 \%$ présentent une asthénozoospermie. Les moyennes de la tératozoospermie et de la grande majorité des anomalies morphologiques sont significativement plus élevées chez les patients asthénozoospermiques.

L'étude des corrélations entre les anomalies morphologiques et la mobilité des spermatozoïdes révèle que toutes les anomalies, sans exception, sont corrélées de façon significative $(p<0,01)$ avec une diminution des mobilités totales et progressives 30 minutes et 4 heures après l'éjaculation. Les anomalies qui semblent avoir le plus d'effets néfastes sur la mobilité sont les anomalies du flagelle, plus spécialement les flagelles courts et les têtes sans flagelle.

Discussion et conclusion : L'altération de la mobilité constitue une des anomalies les plus fréquemment rencontrées chez l'homme infertile. En effet, la majeure partie des patients inclus dans cette étude $(74,5 \%)$ sont asthénozoospermiques. Les résultats de ce travail nous montrent clairement la part de la tératozoospermie dans 
l'altération de la mobilité spermatique et les anomalies du flagelle semblent en être principalement responsables suggérant ainsi des anomalies ultrastrucurales du spermatozoïde touchant l'axonème ou les structures péri-axonémales.

Néanmoins, il est vraisemblable que l'action néfaste des anomalies morphologiques sur la mobilité se fasse en synergie avec d'autres facteurs, environnementaux, immunologiques, biochimiques ou génétiques.

\section{POSTER 34}

Profil spermatique de l'homme consultant pour infertilité du couple dans le centre tunisien (à propos de 4127 cas)

\section{N. GUEDICHE, S. IBALA, M. MEHDI, M. AJINA, A. SAAD}

Service de Cytogénétique et de Biologie de la reproduction, Hôpital " Farhat Hached "Sousse, Tunisie. narjesg@yahoo.fr

Introduction et objectifs : L'infertilité du couple est un état dont la fréquence tend à augmenter et dont l'origine est masculine dans près d'un tiers des cas. L'objectif de ce travail est d'établir le profil spermatique de l'homme consultant pour infertilité dans le centre tunisien à travers l'étude de leurs spermogrammes et d'évaluer la variation de la qualité spermatique inter-individuelle au cours du temps.

Matériel et Méthodes : Nous avons analysé le sperme de 4127 patients ayant consulté pour infertilité du couple au laboratoire de Cytogénétique et de Biologie de la reproduction de l'Hôpital « Farhat Hached » de Sousse entre 2002 et 2007 . Les données concernant l'âge, des patients, l'origine géographique, le type et la durée de l'infertilité ont été recueillis par l'interrogatoire et l'analyse du sperme a été effectuée selon les normes de l'OMS.

Résultats : La majorité des patients sont de nationalité tunisienne $(98,5 \%)$ et $44 \%$ sont originaires de la région de Sousse et sa périphérie. L'âge moyen des patients est de 36,5 ans. Le type d'infertilité est primaire ou secondaire avec des proportions respectives de $77,2 \%$ et $22,8 \%$. La durée moyenne de l'infertilité est de 3,99 ans et a diminué de $7,1 \%$ au cours des 6 années étudiées $(p<0,01)$. Le volume moyen de l'éjaculat est de $2,82 \mathrm{ml}$. Le taux moyen de polynucléaires est de $0,61 \mathrm{mio} / \mathrm{ml}$ et la fréquence de la leucospermie selon les critères de l'OMS $(>1 \mathrm{mio} / \mathrm{ml})$ est de $11,4 \%$. Ce chiffre atteint $15,7 \%$ en abaissant le seuil à $0,5 \mathrm{mio} / \mathrm{ml}$. La nécrozoospermie moyenne est de $24,9 \%$ et la valeur moyenne de la numération des spermatozoïdes est de $69,2 \mathrm{mio} / \mathrm{ml}$ avec des extrêmes allant de 0 à $928 \mathrm{mio} / \mathrm{ml}$ ). L'analyse globale des données du spermogramme montre que celui-ci est normal dans $3,2 \%$ des cas. Près de $7,9 \%$ des patients sont azoospermiques et $13,2 \%$ cryptozoospermiques $(<0,1$ $\mathrm{mio} / \mathrm{ml}$ ) et le volume moyen de l'éjaculat de ces deux groupes est significativement plus bas $(p<0,001)$ que celui des autres patients. Trente minutes après l'éjaculation, la mobilité totale moyenne des spermatozoïdes est de $32,7 \%$ et les patients présentent une asthénozoospermie modérée, sévère et extrême avec des proportions respectives de $35,6 \%, 43,4 \%$ et $21 \%$. Le pourcentage de formes anormales par spermogramme est en moyenne de $65,5 \%$. L'analyse des données du spermocytogramme montre que les anomalies de la pièce intermédiaire à type d'angulation flagellaire $(16,25 \%)$, les têtes microcéphales $(14,66 \%)$ et les anomalies de l'acrosome $(14,46 \%)$ sont les plus fréquentes.

Les taux moyens de nécrozoospermie et de tératozoospermie s'élèvent de façon nette au cours des 6 ans d'étude $(p<0,01)$. Malgré l'absence de significativité, les valeurs moyennes du volume de l'éjaculat et de la mobilité des spermatozoïdes diminuent au fil du temps alors que la numération des spermatozoïdes et des leucocytes semblent augmenter.

Discussion et conclusion : Le profil spermatique de l'homme infertile tunisien semble similaire à ceux retrouvés dans la littérature internationale et un déclin séculaire des caractéristiques spermatiques chez les hommes de couples infertiles semble évident.

\section{POSTER 35}

Relations entre les différents paramètres spermatiques chez les hommes consultant pour infertilité du couple

\section{N. GUEDICHE, S. IBALA, M. MEHDI, M. AJINA, A. SAAD}

Service de Cytogénétique et de Biologie de la reproduction, Hôpital Farhat Hached, Sousse, Tunisie narjesg@yahoo.fr

Introduction et objectifs : Chaque paramètre spermatique est susceptible d'être perturbé et peut dans ce cas être responsable de la dégradation des autres caractéristiques du sperme. Nous essayons à travers ce travail d'établir des corrélations entre les différents paramètres spermatiques afin de mieux interpréter les données du spermogramme et d'améliorer la prise en charge des patients consultant pour infertilité du couple.

Matériel et Méthodes : Nous avons analysé le sperme de 4127 patients ayant consulté pour infertilité du couple au laboratoire de Cytogénétique et de Biologie de la reproduction de l'Hôpital « Farhat Hached » de Sousse entre 2002 et 2007. Les données concernant l'âge des patients, l'origine géographique, le type et la durée de l'infertilité ont été recueillies par l'interrogatoire. Le volume de l'éjaculat, la viscosité, le $\mathrm{pH}$, la numération, la présence de leucocytes, la mobilité, la vitalité et la morphologie des spermatozoïdes ont été évalués selon les normes de l'OMS.

Résultats : La nécrozoospermie et la tératozoospermie sont corrélées positivement entre elles et négativement avec la mobilité et la numération des spermatozoïdes $(p<0,01)$.

L'élévation du $\mathrm{pH}$ semble diminuer la mobilité des spermatozoïdes 4 heures après l'éjaculation, la vitalité, la numération et le voiume de l'éjaculat $(p<0,01)$. Par ailleurs, le taux de leucocytes et le $\mathrm{pH}$ sont corrélés positivement $(p<0,01)$.

Nous trouvons de nombreuses corrélations négatives entre d'une part, les différentes anomalies morphologiques de la tête, de la pièce intermédiaire et du flagelle et d'autre part, la mobilité, la vitalité et la numération des spermatozoïdes.

Discussion et conclusion : Le spermogramme est un examen clé de 1ère intention dans l'exploration d'un couple infertile. Les nombreux paramètres explorés sont étroitement liés les uns aux autres et la perturbation d'un seul facteur, tel que la morphologie des spermatozoïdes ou la présence de leucocytes, est susceptible d'induire un déséquilibre dans presque la totalité des caractéristiques spermatiques. L'interprétation de cet examen reste donc délicate vu qu'il repose sur des critères essentiellement subjectifs et interdépendants. 


\section{POSTER 36}

Intérêt des injections intralésionnelles de vérapamil dans le traitement de la maladie de Lapeyronie

M. HADJSLIMEN, I. BENABDALLAH, M. GASSARA, M. FOURATI, S. KCHAOU, A. BAHLOUL, M.N. MHIRI

Senvice d'urologie CHU Habib Bourguiba. Sfax. Tunisie. Fouratimohamed@yahoo.fr

Introduction : La maladie de Lapeyronie est une pathologie relativement fréquente. Elle est souvent responsable du raccourcissement de l'incurvation du corps caverneux en érection. L'objectif de ce travail est d'évaluer les résultats du traitement par des injections intra-lésionnelles de vérapamil.

Matériel et méthodes : 139 patients atteins de cette maladie ont été traités par des injections intra-lésionnelles de vérapamil. Le nombre d'injection est en moyenne 4,18 injection/patient.

Résultats : l'âge moyen était 55 ans (28-77). L'ancienneté de la maladie varie de 1 à 84 mois. Une pathologie associée a été trouvé : le diabète (13 cas), prostatite $(10 \%)$, traumatisme pénien ancien $(3 \%)$, une cardiopathie ou HTA $(6 \%)$ et une affection psychiatrique ( 2 cas). La douleur était présente chez 73 patients (48\%). Une dysfonction érectile était présente dans $21 \%$ des cas. Le traitement a entrainé la guérison chez 69 patients (50\%) et une amélioration chez 34 patients (25\%). 82 patients $(60 \%)$ ont repris une sexualité normale.

Conclusion : le traitement de la maladie de Lapeyronie par le vérapamil et efficace et bien toléré quelque soit la phase de la maladie.

\section{POSTER 37}

La varicocèle de l'adolescent : faut-il l'opérer ?

\section{HADJSLIMEN, M. GASSARA, M. FOURATI, I. BENABDALLAH, S. KCHAOU,A. BAHLOUL, M.N. MHIRI}

\author{
Senvice d'urologie CHU Habib Bourguiba. Sfax. Tunisie \\ Fourati.mohamed@yahoo.fr
}

Introduction : la varicocèle est une dilatation variqueuse des veines du plexus pampiniforme. C'est une affection facile à diagnostiquer et à traiter. La relation varicocèle-hypofertilité soulève le problème de la conduite thérapeutique.

Matériel et Méthodes : a travers une étude rétrospective portant sur 19 adolescents colligés sur une période de 9 ans, nous avons mené une étude comparative entre deux groupes de patients opères (groupe 1) est non opéré (groupe 2). Le groupe 1 comporte 11 patients, l'âge moyen était de 16 ans 5 mois (15-19). Le groupe 2 compte 8 patients, l'âge moyen était de 16ans 2 mois (15-18). Les circonstances de découverte étaient dominées par les douleurs testiculaires ( 5 cas), elle était fortuite dans 8 cas. Le diagnostic était suspecté cliniquement dans 14 cas et confirmé par écho-doppler dans tous les cas. La varicocèle était bilatérale chez 6 patients dans le groupe 1 et chez 2 patients dans le groupe II. Un spermogramme était réalisé dans tous les cas. Les patients du groupe II ont refusés l'intervention. Dans le groupe I, l'intervention est menée à ciel ouvert dans 10 cas et coelio-chirurgie dans 1 cas. Nos patients ont étés suivis par un spermogramme tous les 6 mois puis dans tous les ans. Le recul moyen était de 6 ans 1 mois dans le groupe $I$ et 5 ans 5 mois dans le groupe II.

Résultats : dans le groupe I une amélioration du spermogramme a était observée dans tous les cas. Dans le groupe II les anomalies étaient persistantes.

Conclusion : la varicocèle pause encore bien des problèmes de prise en charge. A la lumière de ce travail, il parait logique dans l'état actuel de nos connaissances d'en faire la cure chez l'adolescent même à son stade le plus précoce pour prévenir une hypofertilité.

\section{POSTER 38}

\section{Varicocèle et fertilité}

\section{HADJSLIMEN, M. FOURATI, I. BENABDALLAH, M. GASSARA, S. KCHAOU, A. BAHLOUL, M.N. MHIRI}

\section{Service d'urologie CHU Habib Bourguiba. Sfax. Tunisie.} Fourati.mohamed@yahoo.fr

But : étudier les modifications engendrées par le traitement chirurgical de la varicocèle sur les caractéristiques du spermogramme.

Matériel et Méthodes : il s'agit d'une étude rétrospective sur 47 patients opérés en 2 ans. L'évolution a été appréciée sur les données de l'examen clinique et du spermogramme (volume, numération, mobilité et morphologie des spermatozoïdes) réalisé à 3,6 et 9 mois postopératoire.

Résultats : l'âge moyen de nos patients était de 32 ans (19-50 ans). Les indications étaient : la stérilité $(60 \%)$ et la symptomatologie fonctionnelle $(40 \%)$. La varicocèle était bilatérale dans $25,5 \%$ des cas, unilatérale gauche dans $75,5 \%$ des cas et unilatérale droite dans $2 \%$ des cas.

Les patients ont eu une échographie doppler des veines spermatiques préopératoire et ont pu être classés comme suit : varicocèle infra clinique $(61,7 \%)$, grade $1(25 \%)$, grade II $(8,5 \%)$, grade III $(4,5 \%)$ le traitement été chinurgicale dans tout les cas. L'évolution a été marquée par une amélioration de la mobilité des spermatozoïdes. En effet $66 \%$ des patients qui avaient une asthénospermie, celle-ci se réduit à $53 \%, 9$ mois après le traitement.

De même $66 \%$ des patients qui avaient une oligospermie préopératoire, se taux se réduit à $31,9 \%$ trois mois après le traitement. Par ailleurs la morphologie des spermatozoïdes n'a pas été améliorée de façon significative après le traitement.

Conclusion : en cas d'infertilité, le traitement d'une varicocèle permet d'améliorer les paramètres du spermogramme. Cela doit inciter à proposer le traitement de cette varicocèle, surtout si celleci représente le seul élément clinique étiologique de l'infertilité. 


\section{POSTER 39}

Les tumeurs germinales du testicule : à propos de 35 cas

M. HADJ SLIMEN, S. KCHAOU, M. GASSARA, H. KETATA, A. SAHNOUN, K. CHABCHOUB, H. FAKHFAKH, A. BAHLOUL, M.N. MHIRI Service d'Urologie CHU H-Bourguiba, Sfax, Tunisie
kchaou_s@yahoo.fr

Objectif : étudier les différents aspects des tumeurs germinales (TG) du testicule.

Matériel et Méthodes : Etude rétrospective de 35 cas de TG du testicule colligés sur une période de 22 ans. Nous avons répartis nos patients en 2 groupes : $\operatorname{Gr} 1$ ( 13 cas de tumeurs séminomateuses), Gr 2 (22 cas de tumeurs non séminomateuses).

Résultats : Gr 1 : L'âge moyen est de 40 ans. Le bilan d'extension montrait des adénopathies dans 5 cas. L'anatomopathologie trouvait un séminome dans tous les cas. Les malades ont été classés en stade 1 ( 7 cas), stade $2 a$ ( 2 cas), stade $2 b$ ( 2 cas) et stade 2 c ( 2 cas). Un traitement complémentaire était nécessaire: radiothérapie (10 cas), chimiothérapie ( 3 cas) et chirurgie de masse résiduelle (1 cas). Après un recul moyen de 6 ans, tous nos patients étaient en rémission complète. Groupe 2: l'age moyen est de 30 ans. Les ?FP et le BHCG étaient élevés chez 18 patients. II s'agissait d'un carcinome embryonnaire pur ( 7 cas), un tératome immature (1 cas), des tumeurs mixtes avec carcinome embryonnaire majoritaire $(9 \mathrm{cas})$ et avec choriocarcinome majoritaire (5 cas). Dix cas ont été classés en stade 1. Parmi eux, 7 avaient eu une chimiothérapie adjuvante et 3 ont été surveillés ; leur survie à 5 ans était de $100 \%$. Trois patients classés en stade $2 c$ (N3), ont été traités par une chimiothérapie adjuvante et étaient tous décédés après un recul moyen de 3 mois. Parmi les 9 patients classés stade $4(M+), 3$ étaient décédés avant de débuter la chimiothérapie ; les 6 restants avaient reçu une chimiothérapie de type BEP: 4 étaient décédés et 2 étaient en rémission complète après une chimiothèrapie de 2ème ligne (VeIP) et exérèse des masses résiduelles.

Conclusion : Le pronostic des TG du testicule est amélioré par l'association à la chirurgie des nouveaux protocoles de radio et de chimiothérapie. Toutefois, ces tumeurs restent un objet constant de recherche puisqu'elles représentent un modèle de curabilité par une approche multidisciplinaire.

\section{POSTER 40}

Protective effects of estrogens and caloric restriction during aging on various rat testis parameters

\section{K. HAMDEN1, S. CARREAU2, D. SILANDRE2,} C.DELALANDE2, A. EL FEKI1

\author{
1 Department of Animal Ecophysiology, Faculty of Sciences, \\ University of Sfax, Sfax 3018, Tunisia \\ 2 Departments of Biochemistry, University of Caen, 14032, France \\ hamdenkhalid@yahoo.com
}

The aim of the present study was to investigate the effects of 17?estradiol (E2), Peganum harmala extract (PHE) and caloric restriction $(\mathrm{CR})$ on various testis parameters during aging. For this study, 12 month old male rats were treated for 6 months with either E2 or
PHE, or submitted to CR (40\%). Our results show that estrogens and $\mathrm{CR}$ are able to protect the male gonad by preventing the decrease of testosterone and 17?-estradiol levels as well as the decrease of aromatase and estrogen receptor gene expressions. Indeed, 17?estradiol, PHE and CR treatments induced an increase in the superoxide dismutase activities and decreased the activity of testicular enzymes : gamma-glutamyl transferase, alkaline phosphatase, lactate deshydrogenase as well as the aspartate and lactate transaminases in aged animals. In addition, the testicular catalase and gluthatione peroxidase activities were enhanced in 17?-estradiol, PHE and CR-treated rats compared to untreated animals at $18 \mathrm{el}$ of lipid peroxidation. Recovery of spermatogenesis was recorded in treated rats.

In conclusion : Besides a low caloric diet, which is beneficial for spermatogenesis, a protective antioxydant role of estrogens is suggested. Estrogens delay testicular cell damage, which leads to functional senescence and, therefore, estrogens are helpful in protecting the reproductive functions from the adverse effects exerted by reactive oxygen species produced in large quantities in the aged testis.

\section{POSTER 41}

Therapeutic and preventive effects of Ajuga iva aqueous extract on oxidative stress and toxicity in testis and on epididymal spermatozoa in diabetic rats

\section{K. HAMDEN1, M.A. BOUJBIHA1, S. CARREAU2, A. EL FEKI1}

1 Department of Animal Ecophysiology, Faculty of Sciences, University of Sfax, BP 802, Sfax 3018, Tunisia 2 Departments of Biochemistry, University of Caen, 14032, France

The aim of the current study is to investigate the therapeutic and preventive effects of Ajuga iva extract on testis toxicity in diabetic rats induced with alloxan.

64 diabetic (induced with alloxan) pubescent rats were treated during eight weeks with aqueous extract of Ajuga iva in both therapeutic and preventive experiments on testicular toxicity.

Our results showed that the diabete induced a breakdown in testosterone and 17?-estradiol levels in testes and plasma. Besides, a fall in testicular antioxidant capacity appeared by a decrease in antioxidant activities of superoxide dismutase, catalase and glutathione peroxydase. Theses changes enhanced testicular toxicity, confirmed also by an increase in testicular aspartate and alate transaminase (AST \&ALT) and lactate desydrogenase (LDH) activities and the lipid peroxidation level. All these changes lead to a decrease in the total number and motility of epididymal spermatozoa.

The administration of ajuga iva extract three weeks before or after diabetes induction prevented or improved respectively diabetes toxicity in reproductive system.

Conclusion : The data suggested that Ajuga iva aqueous extract had a protective effect on alloxan-induced damage in reproductive system in pubescent rats, by enhancing the testosterone and 17?-estradiol levels in testis and plasma, which protects against oxidative stress, cellular toxicity and maintains the number and motility of spermatozoa via fertility. 


\section{POSTER 42}

Etude de l'effet inter-chromosomique chez des patients porteurs d'une translocation gonosome/autosome

\section{HIREL1, M. ALBERT1,3, P. CLÉMENT4, M. BAILLY2, D. MOLINA GOMES1, A. ESCALONA1, I. HAMMOUD1,3, J. SELVA1,3, F. VIALARD1,3}

1 Laboratoire d'Histologie, Embryologie, Biologie de la reproduction, Cytogénétique et Génétique médicale 2 Service de Gynécologie Obstétrique Hôpital de Poissy St Germain, 78303 Poissy Cedex

3 EA 2493, UVSQ, St Quentin en Yvelines 4 Laboratoire Clément, 93110 Le Blanc Mesnil fvialard@hotmail.com

Introduction : La présence d'une translocation réciproque équilibrée gonosome/autosome est généralement associée à une altération sévère de la spermatogenèse, entraînant fréquemment une azoospermie. Cette altération serait due à la perturbation de la vésicule sexuelle lors de la gamétogenèse, par la formation d'un quadrivalent impliquant les chromosomes $X$ ou $Y$. L'objectif de ce travail est de savoir si ces perturbations pourraient entraîner une modification de la ségrégation des autres chromosomes, et ainsi être associées à un taux d'aneuploïdie augmenté. Ce mécanisme s'appelle " l'effet inter-chromosomique " (EIC).

Populations étudiées : Afin de répondre à cette question, nous avons analysé les spermatozoïdes de 3 patients porteurs d'une translocation autosome/gonosome, un patient fertile $\left(n^{\circ} 1\right)$ et 2 patients infertiles ( $n^{\circ} 2$ et 3 ) ayant une altération sévère de la spermatogenèse. Les résultats ont été comparés à une série de patients témoins.

Méthodes : Les spermatozoïdes ont été analysés par FISH avec un mix contenant la sonde centromérique du chromosome 18 et des sondes spécifiques des bras longs des chromosomes 13 et 21 . Pour les statistiques nous avons utilisé le test du $c$ ?. Les différences statistiques sont considérées comme significatives dès lors que la valeur du $p$ était strictement inférieure à $0,05(p<0,05)$.

Résultats : Les taux d'anomalie pour les chromosomes impliqués dans les translocations sont respectivement pour les patients 1, 2 et 3 de $49.7 \%, 47.7 \%$ et $62.0 \%$. Les taux de malségrégation des chromosomes 13,18 et 21 sont augmentés significativement pour les patients 2 et 3 par rapport à la population témoin, alors que ceux du patient 1 sont similaires. De la même façon les taux d'anomalies des chromosomes 13,18 et 21 sont augmentés pour les patients 2 et 3.

Conclusion : Les résultats sont contradictoires, puisqu'il semble que pour 1 des 3 patients, il n'existe pas d'EIC. Or, ce patient est le seul qui soit normospermique, donc comparable, du point de vue spermatique, à la population témoin. Les anomalies de ségrégation pour les patients 2 et 3 pourraient être dues à l'altération des caractéristiques spermatiques. En effet, les patients oligospermiques présentent également une augmentation des malségrégations. Afin de répondre à cette question, une étude comparative avec des patients à caryotype normal et spermatogénèse altérée est en cours.

\section{POSTER 43}

Evaluation de la participation paternelle dans les grossesses arrêtées d'ICSI du 1er trimestre

\author{
A. JAWADI, G. MERDASSI, I. MADIOUNI, A. CHAKER, F. \\ ZHIOUA, A. ZHIOUA, S. MERIAH \\ Unité de Procréation Médicalement Assisstée Service de \\ Gynécologie Obstétrique. Hôpital Aziza Othmana.Tunis \\ merdassighaya@yahoo.fr
}

Introduction : Un tiers des grossesses d'ICSI se compliquent par un avortement au premier trimestre (1). Plusieurs facteurs féminins étaient impliqués. La participation paternel reste largement discuté. Le but de cette étude était d'étudier l'impact de l'âge paternel ainsi que les caractéristiques spermatiques dans les grossesses arrêtées d'ICSI du premier trimestre.

Patients et méthodes : Nous avons mené une étude rétrospective au sein de l'unité de Procréation Médicalement Assistée de l'hôpital Aziza Othamana portant sur 226 grossesses d'ICSI. Dans notre étude nous avons exclut les femmes âgées de plus que 37 ans et les hommes présentant une azoospermie.

Résultats : Dans notre étude $38.6 \%$ des grossesses d'ICSI étaient arrêtés au 1 trimestre. La comparaison des grossesses évolutives et arrêtées a montré que les avortements précoces ont été associé à un âge paternel plus avancé $(39.02$ vs $40.62, \mathrm{P}<0,05)$

La division de notre population en deux groupes a conclu que les pères âgés de 43 ans ou plus avaient plus de risque d'avoir une grossesse arrêtée précocement. La mobilité et la concentration spermatiques n'ont pas constitué des facteurs prédictifs d'arrêt de la grossesse à un âge précoce.

Conclusion : Cette étude n'est qu'une première approche de l'impact de l'âge paternel dans les avortements précoces en ICSI. Nos résultats sont limités par le faible effectif. Des études prospectives plus larges paraissent indispensables.

Références bibliographiques : 1: Grovani B. Lasala M.D. , Guisseppe Nucera, M.D. , Andrea Gallinelli, M. D., Alessia Nicoli, B. SC. et al. Fertility and sterility Vol. 6, December 2004. 


\section{POSTER 44}

Etude pilote : " Effet des pesticides sur les caractéristiques spermatiques des arboriculteurs en Midi-Pyrénées 》

\author{
V. JOUANOLOU ${ }^{a}$, L. BUJAN ${ }^{b}$, B. CHIRONc, T. MERCIER ${ }^{d}$, \\ S. GRIMBUHLER ${ }^{\text {, B. BOURGOUIN }}{ }^{f}$, J-L. SAGNES $9, \mathrm{~S}$. \\ CHAMBONNIERES $\boldsymbol{g}$, J-L. DUPUPET $\boldsymbol{h}$, P. THONNEAU ${ }^{a}$ \\ a Equipe de recherche en fertilité Humaine (EA3694), Hôpital \\ Paule de Viguier, Toulouse \\ b CECOS Midi-Pyrénées, Hôpital Paule de Viguier, Toulouse \\ c Eurofins-Lara, Laboratoire d'analyses, Toulouse \\ d AFSSA, Maisons-Alfort \\ e Cemagref, Antony $f$ Service Régional de Protection des \\ Végétaux (SRPV), Toulouse \\ $g$ Chambre d'Agriculture du Tarn-et-Garonne, Montauban \\ h CCMSA, Bagnolet jouanolou.v@chu-toulouse.fr
}

Introduction : De nombreuses publications font actuellement état de perturbations importantes de l'appareil reproducteur masculin (baisse de la qualité du sperme et malformations urogénitales) avec comme hypothèse majeure le rôle délétère d'expositions à des produits présents dans notre environnement domestique et/ou professionnel. Certains pesticides ont ainsi été cités comme d'éventuels " perturbateurs endocriniens ", et seraient donc susceptibles d'interférer sur la fertilité masculine avec une altération des caractéristiques spermatiques chez les hommes exposés à ces produits.

Cette étude porte sur l'évaluation des conséquences de l'exposition aux pesticides et plus particulièrement sur le plasma séminal des arboriculteurs. Les principaux objectifs sont d'identifier la population arboricole, évaluer son degré de participation, détailler les expositions professionnelles aux pesticides, (afin d'obtenir une matrice emploi/exposition) et évaluer la faisabilité des dosages par le laboratoire Lara.

Matériel et Méthodes : Cette étude a été conduite dans le département du Tarn-et-Garonne et une population de 34 arboriculteurs, producteurs de pommes, a été incluse. Des prélèvements urinaires accompagnés de questionnaires renseignant sur leur mode de protection ont été demandés. Sur les 34 arboriculteurs, 17 ont été volontaires pour un prélèvement de sperme. Une liste de molécules utilisées a été établie au préalable afin de cibler les analyses laboratoires des échantillons.

Résultats attendus : La collecte des données se terminant courant septembre, le poster sera actualisé d'ici le congrès. La population arboricole du Tarn-et-Garonne devrait être identifiée à l'issue de cette étude. Son degré de participation à une étude comme celle-ci comprenant l'auto administration d'un questionnaire ainsi que des prélèvements biologiques sera déterminé. Les molécules actives les plus utilisées en arboriculture, leur métrologie et leur métabolisme seront connues. Les questionnaires remplis permettront d'évaluer le taux d'exposition des arboriculteurs à ces différentes substances. Les analyses en laboratoire vont nous renseigner sur la faisabilité de ces dosages dans les urines ainsi que dans le plasma séminal.

\section{POSTER 45}

L'orchiépididymite xanthogranulomateuse idiopathique : à propos de 7 cas

\author{
S. KCHAOU, M. HADJ SLIMEN, W. CHARFI, M. GASSARA, \\ H. KETATA, H. FAKHFAKH, A. BAHLOUL, M.N. MHIRI \\ Service d'Urologie CHU Habib Bourguiba, Sfax, Tunisie. \\ kchaou_s@yahoo.fr
}

Introduction : L'orchiépididymite xanthogranulomateuse est une entité qui se définit par son aspect anatomopathologique marqué par la présence de macrophages chargés de lipides.

Matériel et Méthodes : Nous présentons une étude rétrospective de 7 cas d'orchiépididymite xanthogranulomateuse idiopathique colligés sur une période de 25 ans (1982-2007) dans le service d'Urologie de Sfax, se qui fait une fréquence de 2,2 de l'ensemble des orchiépididymites.

Résultats : L'âge moyen était de 51 ans ; l'atteinte testiculaire était prédominante. Aucun cas d'atteinte bilatérale n'a été noté, les antécédents de nos patients était essentiellement des orchiépididymite résistantes au traitement médical dans $42,85 \%$; douleurs scrotales spontanées dans $71,42 \%$ et une tuméfaction scrotale dans $42,85 \%$ des cas. L'examen est souvent pauvre et révèle des douleurs scrotales provoquées $(85,71 \%)$; une masse scrotale $(42,85 \%)$. les explorations radiologiques ont été pratiquées chez $28,57 \%$ des cas, le diagnostic a été porté toujours en postopératoire après orchidectomie par voie scrotale dans $42,85 \%$ des cas dans les formes aigues et par voie inguinale dans les formes pseudo-tumorale $42,85 \%$ des cas. un traitement conservateur après biopsie a été pratiqué dans un seul cas. Un traitement antibiotique a été proposé pour tous les patients; l'évolution a été marquée par l'absence de récidives dans tout les cas, aucun cas de stérilité n'a été noté.

Conclusion : Devant la non spécificité des signes cliniques, biologiques, radiologiques et même macroscopique, le diagnostic positif demeure souvent histologique ce qui permet d'éliminer les autres étiologies. L'orchidectomie par voie inguinale reste la règle à fin d'éliminer une éventuelle tumeur testiculaire.

\section{POSTER 46}

Les sarcomes prostatiques : caractéristiques cliniques et évolutives : à propos de 4 cas

\section{S. KCHAOU, H. KETATA, M. HADJ SLIMEN, M. GASSARA, A. SAHNOUN, K. CHABCHOUB, H. FAKHFAKH, A. BAHLOUL, M.N. MHIRI

\author{
Service d'Urologie, CHU Habib Bourguiba, Sfax, Tunisie \\ kchaou_s@yahoo.fr
}

Objectif : Les sarcomes prostatiques sont des cancers rares qui comptent pour moins de $0,1 \%$ de l'ensemble des tumeurs prostatiques; on se propose d'exposer les caractéristiques cliniques et évolutives de cette pathologie.

Matériel et Méthodes : Etude rétrospective, série de 4 observations sur une période de 20 ans observées chez des hommes d'âge moyen de 54 ans (31-71).

Résultats : Les symptômes révélateurs n'étaient pas spécifiques et 
étaient à type de signes d'irritation vésicale dans tous les cas, d'obstruction urinaire (75\%) et d'hématurie initiale (25\%). Le toucher rectal a révélé dans tous les cas une prostate suspecte indurée avec infiltration du plancher vésical dans 1 cas. Le bilan morphologique a comporté une échographie sus-pubienne qui a montré dans tous les cas un très volumineux processus tumoral hétérogène prostatique, une urétéro hydronéphrose par infiltration du plancher vésical (50 $\%$ ). Le bilan d'extension a révélé un envahissement osseux au niveau du bassin chez un patient, des métastases pulmonaires (2 cas), hépatiques ( 1 cas). Tous les patients ont eu une biopsie transrectale de la prostate, associée dans 2 cas à une résection endoscopique à visée mictionnelle. Le diagnostic de certitude a été fait par l'histologie il s'agissait de rhabdomyosarcome (1 cas), de leiomyosarcome ( 2 cas) et de fibrosarcome chez le plus jeune patient. Le traitement s'est limité à une chimiothérapie systémique (3 cas) et une abstention thérapeutique chez un patient en raison de son mauvais état général. L'évolution a été fatale dans tous les cas, après 4 mois de survie en moyenne, avec apparition d'une extension ischio-pelvienne rapide de la tumeur ( 3 cas), de métastases osseuses (2 cas) et d'un syndrome occlusif par envahissement rectal ayant nécessité une colostomie de proche amont (1 cas).

Conclusion : Les sarcomes prostatiques se caractérisent par leur extension locorégionale importante et rapide, leur haut grade de malignité et leur mauvais pronostic.

\section{POSTER 47}

\section{Rhabdomyosarcome para-testiculaire}

\section{S. KCHAOU, H. KETATA, M. HADJ SLIMEN, W. CHARFI, A. SAHNOUN, H. FAKHFAKH, A. BAHLOUL, M.N. MHIRI

\author{
Service d'Urologie CHU Habib Bourguiba, Sfax, Tunisie
} kchaou_s@yahoo.fr}

Objectif : Etudier les caractéristiques cliniques, para-cliniques et thérapeutiques des thabdomyosarcomes para-testiculaires (RPT).

Matériel et Méthodes : Etude rétrospective (1982-2007) portant sur 6 cas de RPT. L'âge moyen était de 20 ans (10-35 ans). Tous les patients ont eu une orchidectomie par voie inguinale. Le bilan d'extension a comporté une radiographie du thorax, une échographie abdominale et un scanner thoraco-abdominopelvien. Nous avons adopté la classification IRS (intergroup Rhabdomyosarcoma Study) dans la stadification et la prise en charge thérapeutique.

Résultas : Les circonstances de découverte étaient : une augmentation progressive du volume testiculaire ( 3 cas), une grosse bourse apparue dans les suites d'un traumatisme scrotal (1 cas), une masse inguinale ( 1 cas) et une masse cervicale (1 cas). L'examen clinique a révélé une tuméfaction scrotale dure dans tous les cas associée à des adénopathies inguinales dans 2 cas et une adénopathie cervicale dans 1 cas. Le diagnostic a été confirmé par l'examen anatomopathologique de la pièce d'orchidectomie. II s'agissait d'un RPT embryonnaire (4 cas), d'une forme polymorphe (1 cas) et d'un RPT bien différencié (1 cas). Le bilan d'extension était négatif dans 2 cas. Il a montré des ganglions rétropéritonéaux ( 3 cas), des ganglions médiastinaux (1 cas) et des métastases pulmonaires ( 1 cas). La tumeur était classée stade IV ( 3 cas), stade I ( 2 cas) et stade II (1 cas). Un traitement adjuvant, comportant une polychimiothérapie adjuvante ( 5 cas) et une radiothérapie adjuvante (1 cas) a été instauré. Trois patients sont décédés après un recul de 3,12 et 24 mois. Deux patients sont en vie après un recul de 46 mois.
Conclusion : Les RPT sont des tumeurs malignes d'évolution rapide qui touchent le sujet jeune. Le diagnostic est histologique. Le traitement associe la chirurgie, la chimiothérapie et la radiothérapie. Leur pronostic reste redoutable malgré la diversité des moyens thérapeutiques disponibles.

\section{POSTER 48}

Répercutions des anomalies gamétiques sur le bilan biologique de fécondation assistée (Etude rétrospective à propos de 92 couples)

S. KEBAILI1, M. AJINA1, M. BOUGMIZA2, A. CHAID1, M. MEHDI1, M. GAHMOUL1, H. SAIDI1, H. KHAIRI1, A. SAAD 1

1 Unité de Médecine de la Reproduction, Hôpital F Hached, Sousse, Tunisie 2 Département de Médecine communautaire, Faculté de Médecine Sousse, Tunisie Kebaili.sahbi@yahoo.fr

Introduction : Les anomalies spermatiques altère la segmentation embryonnaire à un stade tardive (Blastocyste) par contre les anomalies ovocytaires répercute sur l'embryon à un stade très précoce (Zygote). L'objective de notre étude est de déterminer les profils gamétiques des couples candidats à la fécondation assistée et de vérifier l'effet de ces anomalies sur la qualité de la fécondation et la segmentation embryonnaire.

Matériel et Méthodes : Etude rétrospective à propos de 92 couples qui ont bénéficié de 92 cycles d'injection intra cytoplasmique d'un spermatozoïde (ICSI) en début de l'année 2008. Chaque couple a bénéficié d'une étude morphologique des spermatozoïdes après filtration sur gradient de pur sperme et une étude morphologique des ovocytes après leurs dénudations.

Résultats et Discussions : L'analyse statistique des paramètres spermatiques a trouvé que le nombre moyen des spermatozoïdes était de 25,9 millions $/ \mathrm{ml}$, le \% moyen des formes anormales était de $76.7 \%$ et la mobilité moyenne $(a+b)$ était de $17.3 \%$. Les taux moyens, de maturation, de dysmorphie ovocytaire, de fécondation, d'obtention de zygote type l étaient respectivement de $84 \%, 64 \%, 63 \%$ et $48 \%$. Le taux de grossesse était de $33,9 \%$. La comparaison des paramètres spermatiques avec le taux de fécondation n'a trouvé de différence significative. De même pour la comparaison entre le taux moyen de maturation ovocytaire et le taux de fécondation $(p=0,57)$ ainsi entre taux de $\mathrm{Zl}$ chez les patientes ayant eu une grossesse et celles dont la B HCG était négative ( $p=0,27)$. En étudiant le taux de dysmorphie ovocytaire et le taux de fécondation, on a remarqué que la relation était inversement proportionnel. Par contre la différence était significative entre taux de fécondation et le taux de grossesse $(p=$ 0,036 ).

Conclusion : Le taux de grossesse augmente chez les couples où la qualité gamétique était normale, mais la différence était non significative. Dans notre travail, Le taux de fécondation n'était pas influencé par les pourcentages moyens des anomalies gamétiques de même pour le taux de maturation ovocytaire. Par contre le taux de grossesse était significativement sensible au taux de fécondation. Le taux de fécondation est un des meilleurs indicateurs de grossesse.

Références bibliographiques :

1) Granot l et Dekel N. Preparation and evaluation of oocytes for intracytoplasmic sperm injection. Textbook of assisted reproductive technique, second edition p115-124.

2) Mermillod $P$ et Lannou L: Maturation ovocytaire in vivo et in vitro chez les mammifères: Ovocyte et Embryon, P 95- 110.

3) MGR Hull : Female age and fecundity Fertility and Sterility 1995 p181-185. 


\section{POSTER 49}

Mise en place d'une barrière hémato-testiculaire in vitro comme méthode alternative et complémentaire à l'expérimentation animale pour l'étude des effets des perturbateurs de la fonction endocrinienne

\section{A. LEGENDRE1, S. DESMOTS1, A. LECOMTE1, F. ROBIDEL1, O. DUPONT1, P..FROMENT2, R. HABERT3, E. LEMAZURIER1}

1 Laboratoire de Toxicologie Expérimentale - INERIS - F 60550 Verneuil en Halatte 2 INRA - F 37380 Nouzilly 3 INSERM U566CEA-Université Paris 7 - F 92265 Fontenay aux Roses audrey.legendre@ineris.fr

Introduction : L'identification des molécules toxiques pour la reproduction et la compréhension de leur mécanisme d'action représentent un challenge scientifique majeur. Actuellement, seules des méthodes in vivo sont reconnues par les autorités compétentes pour tester cette reprotoxicité : la mise en place de méthodes alternatives constitue donc un autre grand défi pour ces prochaines années.

L'objectif de ce travail consiste au développement d'un modèle in vitro de la barrière hémato- testiculaire dont le rôle in vivo est primordial pour la défense des tubules séminifères, siège de la spermatogenèse, face à l'agression des xénobiotiques. Cette méthode, à la fois alternative et complémentaire à l'expérimentation animale, sera appliquée à l'étude des effets des perturbateurs de la fonction endocrinienne (PE) sur la reproduction mâle.

Matériel et Méthodes : Ces travaux reposent sur la mise au point d'un système de culture original constitué de cellules testiculaires primaires de rat (cellules de Sertoli, germinales et péritubulaires) cultivées en chambre bicamérale dans une matrice extracellulaire artificielle. La validation du modèle est effectuée par des études de morphologie et de fonctionnalité de la barrière et du maintien de processus de spermatogenèse in vitro.

Résultats : Les premiers résultats ont mis en évidence une organisation en structure cord-like des cellules germinales et sertoliennes, au sein de la matrice extracellulaire, typique des tubules séminifères in vivo. De plus, la présence de jonctions serrées sertoliennes au sein de ces structures et la résistance électrique intraépithéliale significative mesurée dans les chambres polarisées corrèlent avec les caractéristiques in vivo de la présence d'une BHT.

Discussion et Conclusion : La fonctionnalité de la BHT reste néanmoins à valider et la mise en évidence du maintien de la spermatogenèse est en cours d'analyse par cytométrie de flux. Cette technique permet de classer les cellules selon leur ploïdie $(4 \mathrm{C}, 2 \mathrm{C}$, et $C$ ) et d'observer l'évolution de la répartition des différentes populations cellulaires actrices de la spermatogenèse durant la totalité de la période de culture.

Une fois mise au point, cette BHT in vitro permettra de tester la toxicité potentielle de molécules à caractère perturbateur endocrinien et participera à la compréhension de leur mécanisme d'action, en particulier leur interaction avec les $A B C$ transporteurs comme la $P$ glycoprotéine.

\section{POSTER 50}

Effets du MEHP (mono-2-éthylhexyl phtalate), sur le développement du testicule fcetal et néonatal de souris : étude in vitro

\section{A. LEHRAIKI (1), C. RACINE (1), R. HABERT (1), C. LEVACHER (1)}

(1) UMR Gamétogenèse et Génotoxicité, INSERM U566, CEA, Université Paris 7-Denis Diderot, Fontenay-aux-Roses, France abdelali.lehraiki@cea.fr

Introduction : Les phtalates sont des substances chimiques classées parmi les perturbateurs endocriniens et largement distribuées dans l'environnement. Des études in vivo (in utero) et in vitro chez le rat ont montré que ces molécules exercent un effet délétère sur le développement précoce du testicule $[1,2]$, entraînant des anomalies de la fonction testiculaire à l'âge adulte [3] mais les mécanismes de l'action reprotoxique de ces molécules restent largement inconnus et les études réalisées jusqu'à présent se réfèrent quasi exclusivement au modèle rat. Nous avons étudié l'effet du MEHP (mono-2-éthylhexyl phtalate), métabolite actif du DEHP (di-2-éthylhexyl phtalate), considéré parmi les phtalates comme l'un des plus produits dans le monde, sur le développement testiculaire chez la souris pendant la vie fœtale et néonatale.

Matériel et Méthodes : Nous avons utilisé un modèle original de culture organotypique de souris déjà caractérisé dans notre laboratoire [4]. Les testicules sont explantés à 13,5jpc, à 18,5 jpc (jour postcoitum) et à 2 jpp (jour post-partum) puis mis en culture pendant trois jours en présence ou en absence de MEHP (20 et $200 \mu \mathrm{M})$ et/ou d'Hormone Lutéinisante (LH) et les milieux sont changés toutes les 24 heures.

Résultats et discussion : Le MEHP diminue le nombre de gonocytes pendant les deux périodes de prolifération germinale (vie fœtale et vie néonatale) avec une plus forte sensibilité pendant la première phase de prolifération. Cet effet délétère résulte d'une augmentation de l'apoptose de ces cellules. La diminution du nombre de gonocytes par le MEHP est la même en conditions basale et stimulée par la LH. En outre, le MEHP augmente la prévalence des gonocytes plurinucléés uniquement en fin de vie fcetale. Parallèlement le MEHP stimule la production de testostérone en conditions basales pendant toute la vie fœetale et néonatale alors qu'en conditions stimulées par la $\mathrm{LH}$, le MEHP inhibe la production de testostérone en fin de vie fœtale et est sans effet en début de vie fœtale.

Conclusion : Nous pouvons conclure de l'ensemble de ces résultats:

- que le MEHP exerce un effet délétère direct sur la gamétogenèse et la stéroïdogenèse du testicule foetal en culture organotypique pendant toute la vie fœtale et néonatale avec des différences de sensibilité en fonction de l'âge et des conditions de culture.

- que contrairement à ce qui a souvent été postulé en raison des observations faites chez le rat, les altérations de la lignée germinale et de la stéroïdogenèse par le MEHP sont deux phénomènes indépendants.

Références bibliographiques :

[1] Ferrara $D$ et al (2006) Endocrinology 147: 5352-5362.

[2] LiH and Kim KH (2003) Biol Reprod 69: 964-1972.

[3] Foster PM (2006) Int J Androl 29:140-147 ; [4] Livera G et al (2006) Cell Tissue Res 324. 


\section{POSTER 51}

Cryptorchidie et Infertilité : quand faut-il opérer ?

\section{S. MEDDEB, J. ZAAFRANE, A.CHAIB, S. BOUGUIZENE, M. BIBI, H. KHAIRI \\ Service de Gynécologie Obstétrique Farhat Hached Sousse sawsen.lina@hotmail.fr}

La cryptorchidie se définit comme un testicule spontanément et en permanence situé en dehors du scrotum en un point quelconque de son trajet normal de migration. Ainsi, le testicule cryptorchide peut se trouver en position intra-abdominale, à l'intérieur du canal inguinal, à son orifice externe ou à la racine de la bourse. Elle touche 3 à 5 $\%$ des nouveau-nés et 0,8 à $1,6 \%$ des enfants de un an, pour rester stable jusqu'à la puberté.

Les facteurs potentiels d'infertilité du testicule cryptorchide sont multiples : l'hyperthermie ; la qualitè du tissu testiculaire propre ; en effet, la cryptorchidie relève souvent d'un hypogonadisme hypogonadotrophique et plus le testicule est haut situé plus l'anomalie est potentiellement importante ; les altérations associées de la voie spermatique profonde : dissociations épididymo-testiculaires, atrésie voir agénésie de l'épididyme ou du canal déférent ou de l'anse épididymo-déférentielle ; les lésions iatrogènes lors de l'intervention sur le testicule cryptorchide ou de tout autre pathologie ayant nécessité un abord chirurgical du canal inguinal.

L'objectif de ce travail est de répondre à travers une revue de la littérature à la question: quel effet a l'âge de traitement de la cryptorchidie sur la fertilité ? Et donc de savoir s'il existe une altération progressive du testicule non descendu avec le temps ou si l'infertilité est la conséquence d'une alternation primitive du testicule.

Les réponses à ces deux questions sont très discordantes; quelques auteurs préconisent un traitement précoce avec une récupération de $90 \%$ de la fonction et de l'histologie normale des testicules; alors que d'autres n'ont pu mettre en évidence aucune corrélation entre les variables de la fertilité et l'âge du traitement. Nous passons en revue les différentes réponses à cette question fondamentale de l'âge auquel il faut prendre en charge et traiter la cryptorchidie qui sont loin d'être formelles dans la littérature.

\section{POSTER 52}

Résultats de l'intracytoplasmic injection (ICSI) avec des spermatozoides frais ou après cryopréservation testiculaire : étude comparative

\section{S. MEDDEB, C. LABROUSSE, F. DUMAS}

Service de Gynécologie Obstétrique, Hopital Hotel Dieu sawsen.lina@hotmail.fr

Objectif : Comparer les résultats de l'intracytoplasmic sperm injection (ICSI) avec des spermatozoïdes frais ou après cryopréservation des spermatozoïdes testiculaires chez des patients avec azoospermie obstructive ou non obstructive.

Matériel et Méthodes : Analyse rétrospective de 60 cycles d'ICSI (32 frais, 28 cryopreservation).

Résultats : II n'y'a pas de différence statistiquement significative des différents paramètres examinés entre le sperme frais et celui obtenu par cryopreservation du tissu testiculaire. Les taux de fertilisation étaient respectivement de $61.6 \%$ et $61.7 \%$, les taux de grossesse par transfert embryonnaire étaient respectivement de $29.1 \%$ versus $25 \%$ et les taux d'accouchement $85.7 \%$ versus $80 \%$.

Conclusion : L'ICSI avec sperme obtenu par cryopréservation testiculaire permet d'obtenir des taux de fertilisation et de grossesses aussi satisfaisant que ceux obtenus avec du sperme frais. En plus cette cryopréservation peut servir de source de spermatozoïdes pour les éventuels cycles ultérieurs d'ICSI.

\section{POSTER 53}

Intérêt de la mesure de la fragmentation de l'ADN spermatique dans les cas d'altération morphologique des spermatozoïdes

\section{MEHDI, L. KHANTOUCHE, N. GUEDDICHE, A. SAAD}

Laboratoire de Cytogénétique et Biologie de la Reproduction, CHU Farhat Hached. Sousse. Tunisie hbsmahdi@yahoo.fr

Introduction : L'objectif de notre étude est de mesurer la fragmentation de l'ADN des spermatozoïdes des hommes qui présentent une altération sévère du spermogramme et de déterminer les éventuelles corrélations qui peuvent exister entre la fragmentation de l'ADN spermatique et les paramètres spermatiques.

Patients et Méthodes : Nous avons donc sélectionné 90 sujets, des patients ayant une altération de la mobilité spermatique : asthénozoospermie $(n=30)$, des patients ayant une altérartion de la morphologie spermatique : tératozoospermie $(n=30)$ et des sujets avec bonnes caractéristiques du spermogramme $(n=30)$ qui vont jouer le rôle de témoins. La fragmentation de l'ADN spermatique est mesurée par la technique TUNEL (Terminal deoxynucleotidyl transferase-mediated dUDP nick-end Labelling). Pour chaque sperme, au moins 300 spermatozoïdes sont analysés.

Résultats : Pour les patients ayant une asthénozoospermie, nous n'avons pas trouvé de différence significative pour l'index de fragmentation de l'ADN spermatique (DFI) par rapport au groupe témoin (respectivement $9.46 \% \pm 8.68$ et $8.19 \% \pm 6.84$, différence non significative). En plus, nous n'avons pas trouvé de corrélation entre la mobilité et la fragmentation de l'ADN spermatique. Alors que le taux de fragmentation de l'ADN est plus élevé avec une différence hautement significative chez les patients avec tératozoospermie par rapport au groupe témoin (respectivement $21.37 \% \pm 17.26$ et $8.19 \%$ $\pm 6.84, p<0.01$ ). Il existe une corrélation positive entre les formes atypiques et le DFI $(r=0.44, p<0.01)$ et particulièrement avec les spermatozoïdes microcéphales ou avec anomalie de l'acrosome. Le DFI est particulièrement plus élevé quand la valeur des formes atypiques dépasse $90 \%$.

Conclusion : notre étude montre que les affaiblissements des paramètres spermatiques sont associés à une augmentation de la fragmentation de l'ADN spermatique. Cette association est en rapport strict avec les formes atypiques. La tératozoospermie est donc un paramètre critique de l'hypofertilité masculine et quand elle dépasse la valeur $90 \%$ de formes atypiques, elle serait un signe d'appel pour l'analyse de la fragmentation de l'ADN spermatique. 


\section{POSTER 54}

Effets de la centrifugation sur gradient de densité sur les anomalies chromosomiques et sur la fragmentation de l'ADN des spermatozoïdes

\section{MEHDI, K. LETAIEF, S. BRAHEM, H. EL GHEZEL, A. SAAD}

Laboratoire de Cytogénétique et Biologie de la Reproduction, CHU Farhat Hached. Sousse. Tunisie hbsmahdi@yahoo.fr

Introduction : Le but de cette étude est d'évaluer l'effet de la centrifugation sur gradient de densité sur les aneuploïdies et sur la fragmentation de l'ADN des spermatozoïdes des hommes infertiles qui présentent une anomalie au spermogramme.

Matériel et Méthodes : 50 prélèvements spermatiques des patients infertiles ayant au spermogramme une tératozoospermie sévère ( $>80 \%$ formes anormales) ont été subdivisés en deux groupes : groupe $1(n=30)$ des patients chez qui une détection du taux d'aneuploïdies spermatiques a été faite par FISH sur spermatozoïdes avec des sondes centromériques des chromosomes $X, Y$ et 18 sur les trois fractions de gradient de densité discontinu de SilSelect après centrifugation. Pour chaque patient, 500 noyaux spermatiques par fraction de gradient ont été analysés au microscope à épifluorescence. Le groupe $2(n=20)$ des patients chez quil la technique TUNEL a été utilisée pour mesurer la fragmentation de l'ADN spermatique sur les différentes fractions de préparation du sperme par gradient discontinu de Sil Select. Un minimum de 300 spermatozoïdes par fraction de gradient de densité et par sujet a été analysé.

Résultats : Nous avons trouvé une diminution nettement significative des aneuploïdies spermatiques dans les différentes fractions du gradient de densité : $50 \%, 70 \%$ et $90 \%$, respectivement pour la disomie totale ( $10.32 \%$ vs $7.36 \%$ vs $4.43 \%)$, pour la diploïdie totale (3.2\% vs $1.9 \%$ vs $1.23 \%)$ et pour la nullisomie totale $(5.11 \%$ vs $3.18 \%$ vs $2.14 \%$ ), $p<0.01$. Nos résultats ont montré une différence hautement significative du taux de fragmentation de I'ADN spermatique avant et après traitement du sperme (respectivement $38.15 \pm 7.81 \%$ et $18.90 \pm 8.18 \%, p<0.01$ )

Conclusion : Nos résultats justifient que la préparation du sperme par centrifugation sur gradient de densité discontinu permet une sélection des spermatozoïdes contre les aneuploïdies spermatiques d'une part et contre la fragmentation de l'ADN spermatique d'autre part, confirmant les vertus de cette technique dans l'assistance médicale à la procréation.

\section{POSTER 55}

Préservation de la fertilité chez l'adolescent de sexe masculin: une expérience de plus de $\mathbf{2 0}$ ans au CECOS du CHU de Rouen

S. MENON1, N. MOUSSET-SIMÉON1, L. SIBERT3, M.H. CHELLI1, S. MAZURIER1, L. MASSÉ1, V. DUCHESNE1, R. SAIDI1, B. MACÉ1, N. RIVES2

1 Laboratoire de Biologie de la Reproduction - CECOS, EA 4308 "Spermatogenèse et Qualité du gamète mâle", CHU Hôpitaux de Rouen, 76031 Rouen 2 Laboratoire de Biologie de la Reproduction - CECOS, EA 4308 "Spermatogenèse et Qualité du gamète mâle", Centre d'Investigation Clinique Inserm 0204 , Centre Hospitalier Universitaire de Rouen, 76031 Rouen cedex 3 Service d'Urologie, EA 4308 "Spermatogenèse et Qualité du gamète mâle" Centre Hospitalier Universitaire Rouen, 76031

Rouen cedex nathalie.rives@chu-rouen.fr

Introduction : Les traitements anti-cancéreux ont des effets néfastes sur les gonades à court et long termes. Quinze à trente pour cent des jeunes adultes ayant survécu à un cancer sont stériles. Préserver leur fertilité avant tout traitement gonadotoxique est en conséquence une nécessité. L'objectif de ce travail est d'ètudier la faisabilité d'une congélation préventive de spermatozoïdes chez les adolescents et d'évaluer leur fertilité après traitement.

Matériel et méthodes : Une étude rétrospective a été menée au CECOS (Centre d'Etude et de Conservation des CEufs et du Sperme humain) du Centre Hospitalier Universitaire de Rouen. Cent cinquante six adolescents âgés de 13 à 20 ans ayant consulté, de Janvier 1984 à Décembre 2006, en vue d'une congélation préventive de spermatozoïdes, ont été inclus. L'âge, les antécédents urologiques, l'indication de l'auto conservation, le type histologique et le stade du cancer le cas échéant, ainsi que les paramètres spermatiques au moment du diagnostic, ont été analysés pour chaque patient. Les patients, pour qui la conservation de gamètes a été effective, ont été interrogés au moyen d'un questionnaire sur leur fertilité à distance du traitement. Les paramètres spermatiques après traitement ont été analysés chez 22 patients.

Résultats : Une congélation de spermatozoïdes a pu être réalisée pour une grande majorité $(88.5 \%)$ de patients. Au moment du diagnostic, $2.6 \%$ des adolescents présentaient une azoospermie. Dans $84 \%$ des cas, l'indication de la cryopréservation était la survenue d'un cancer. Seuls les patients porteurs d'une tumeur osseuse métastatique avaient une altération significative de leurs paramètres spermatiques. Une biopsie testiculaire a été réalisée chez quatre patients, avec congélation possible de spermatozoïdes pour trois d'entre eux. Après traitement, neuf des vingt-deux patients ayant effectué un spermogramme présentaient une azoospermie. Enfin, onze couples ont exprimé un désir de grossesse. Huit seulement ont pu accéder au statut de parents : cinq suite à la survenue d'une grossesse spontanée, deux grâce à une assistance médicale à la procréation (AMP) utilisant du sperme frais éjaculé et un au moyen d'un don de sperme. Trois procédures d'AMP utilisant des paillettes autoconservées ont échouées.

Discussion et conclusion : Ces résultats confirment que la congélation préventive de sperme est une procédure efficace et accessible à une majorité d'adolescent sans discrimination lié à l'âge. Elle doit, par conséquent, être proposée systématiquement quelque soit le type de pathologie considérée et son stade. Dans les situations d'échec au recueil ou d'azoospermie, une biopsie testiculaire en vue d'une extraction de spermatozoïdes doit être proposée. 


\section{POSTER 56}

\section{Optimisation d'un protocole de congélation de tissu testiculaire de rat prépubère}

\section{METTON, J.P. MILAZZO, A.BIRONNEAU, M.H. CHELLI, A. PERDRIX, B. MACÉ, N. RIVES}

Laboratoire de Biologie de la Reproduction - CECOS, EA 4308 "Spermatogenèse et Qualité du gamète mâle", CHU Hôpitaux de Rouen, 76031 Rouen nathalie.rives@chu-rouen.fr

Introduction : Différents paramètres sont susceptibles d'altérer la qualitè du tissu testiculaire après décongélation : le type et la concentration de cryoprotecteur utilisé, le temps d'incubation dans le milieu de congélation et la procédure de congélation. L'objectif de notre étude a été d'évaluer l'impact des variations des conditions de congélation sur la qualité du tissu testiculaire de rat prépubère après décongélation afin d'identifier les paramètres optimaux de congélation de tissu testiculaire immature puis à partir du protocole sélectionné de définir la taille des fragments tissulaires et le mode de conditionnement le plus adapté.

Matériel et Méthodes : Des fragments de testicules provenant de rats Wistar prépubères de 6 jours sont incubés à température ambiante (RT) ou à $4^{\circ} \mathrm{C}$ dans un milieu de congélation contenant du sucrose $(0.05 \mathrm{M})$ et un cryoprotecteur (DMSO ou PROH) pendant $30 \mathrm{~min}$ ou $60 \mathrm{~min}$. Le tissu servant de témoin est le tissu non congelé et les différents protocoles testés sont les suivants : avec le DMSO $1,5 \mathrm{M}, 4$ protocoles de congélation sont comparés (demi testicule vs testicule entier - cryotube vs paillette) et avec le $\mathrm{PROH}, 14$ protocoles de congélation sont comparés : $\mathrm{PROH}$ à $1,5 \mathrm{M}$ vs $\mathrm{PROH}$ à $3 \mathrm{M}$ Temps d'incubation : $30 \mathrm{~min}$ vs $60 \mathrm{~min}$ - Température d'incubation : ambiante vs $4^{\circ} \mathrm{C}$ - Seeding : avec vs sans. Après décongélation, la morphologie des tubes séminifères est évaluée ce qui aboutit à l'établissement de scores d'altérations tissulaires. Plus le score est élevé, plus le tube séminifère est altéré. Une moyenne est réalisée sur les scores d'une trentaine de tubes séminifères. A partir de la condition de congélation la plus optimale, une décongélation de fragment tissulaire est effectuée et une culture des fragments tissulaires est réalisée pendant 15 jours à $32^{\circ} \mathrm{C} 5 \% \mathrm{CO} 2$. Une évaluation morphologique des tubes séminifères permettant de déterminer la densité cellulaire intratubulaire est réalisée à $\mathrm{J} 7, \mathrm{J9}$ et $\mathrm{J} 15$ après le début de la culture. Un marquage immunocytochimique avec l'anticorps antiPCNA est également pratiqué.

Résultats : D'après l'étude histologique, la meilleure condition de congélation avec le $\mathrm{PROH}$ repose donc sur : une incubation à $4^{\circ} \mathrm{C}$, avec une concentration de $\mathrm{PROH}$ à $3 \mathrm{M}$ pendant 30 minutes ou de $\mathrm{PROH}$ à $1.5 \mathrm{M}$ pendant 60 minutes. Le seeding donne des résultats, comme prévu, très aléatoires. Un fragment de testicule de $7,5 \mathrm{mg}$ congelé dans un milieu contenant du DMSO à $1,5 \mathrm{M}$ et $0,05 \mathrm{M}$ de sucrose permet une meilleure conservation tissulaire par comparaison à un poids de $15 \mathrm{mg}$. De plus, l'utilisation des cryotubes semble préférable à celle des paillettes. Une augmentation de la densité cellulaire (cellules de Sertoli et spermatogonies), du diamètre des tubes séminifères ainsi que la présence d'une activité mitotique est détectée après culture des fragments testiculaires frais ou congelés (conditions optimales pour le DMSO). Des spermatocytes I aux stades leptotène, zygotène et pachytène ont pu seulement être observés sur les lames de culture de tissu non congelé. Les stades leptotène et zygotène ont aussi pu être obtenus pour la culture de tubes séminifères décongelés.
Conclusion : Les meilleures conditions testées avec du PROH présentent toujours un taux d'altérations tissulaires plus élevé que celui retrouvé avec le DMSO. Un contact trop long avec le PROH à forte concentration semble néfaste pour le tissu. Le DMSO, bien que plus toxique, est donc préférable pour la bonne conservation du tissu testiculaire immature après décongélation et permet de préserver la fonctionnalité des cellules germinales et somatiques du testicule prépubère.

\section{POSTER 57}

Evaluation de la sexualité avant et après chirurgie de l'hypertrophie bénigne de la prostate

\section{M.A. MSEDDI, A. SAHNOUN, M. FOURATI, M. HADJSLIMEN, K. CHABCHOUB, H. KETATA, H. FAKHFEKH, A. BAHLOUL, M.N. MHIRI}

Service d'urologie CHU Habib Bourguiba de Sfax. mseddi_amine@yahoo.fr

Introduction : l'hypertrophie bénigne de la prostate (HBP) symptomatique, est l'une des pathologies les plus fréquente en urologie, son retentissement sur la qualite de vie des patients et surtout sur leur vie sexuelle est assez fréquent, le but de cette étude est d'évaluer la sexualité de ces patients avant et après traitement chirurgical de leur hypertrophie prostatique.

Matériel et Méthodes : Notre étude est prospective réalisée au service d'urologie du CHU Habib Bourguiba de Sfax entre le $1^{\mathrm{er}}$ Mars 2008 et le 31 juillet 2008 , concernant une série de 18 patients, âgés entre 50 et 80 ans, hospitalisés pour chirurgie de leur HBP et gardant une activitée sexuelle. Chaque patient a répondu à un questionnaire pré opératoire et 3 mois après chirurgie comprenant I-PSS, DAN-PSS-1, et IIEF.

Résultats : L'âge moyen de nos patients est de 66 ans. 8 patients sont hypertendus, 4 diabétiques, 2 coronariens et 9 n'ont pas d'antécédents médicaux. 14 patients $(77,8 \%)$ n'avaient pas de dysfonction érectile (DE) avant l'opération, 9 d'entre eux avaient une activité sexuelle réduite ( $<4$ rapport/mois). 4 patients parmi eux 2 diabétiques, avaient déjà une DE à type de dysérection (4 cas), trouble de l'éjaculation ( 3 cas) et un trouble de la libido chez un patient.

Dix patients ont eu une résection endoscopique de la prostate (REP) et 6 ont eu une adénomectomie trans-vésicale (ATV). 6 patients ne soufrant pas de DE (43\%) ont estimé que leur fonction sexuelle avait changé après l'intervention ( $50 \%$ par RTUP, $50 \%$ par ATV), les plaintes invoquées sont une dysérection chez un patient $(7 \%)$, une diminution de la libido chez 3 patients $(21,5 \%)$, une éjaculation rétrograde chez 5 patients $(35,7 \%)$, une diminution de l'orgasme chez 2 patients $(14,3 \%$ ) et des troubles multiples chez 4 patients dont un diabétique. Cependant parmi ces 14 patients $6(43 \%)$ se sont déclarés très satisfait de leur sexualité et un patient diabétique ayant une activité sexuelle préopératoire réduite a noté une amélioration de son désir sexuel et une augmentation du nombre de ses rapports sexuels. Enfin, 4 patients souffrant déjà d'une DE n'ont pas noté d'amélioration

Discussion et Conclusion : La chirurgie pour HBP donne d'excellents résultats sur le plan mictionnel. Cependant, le retentissement observé sur la vie sexuelle dans près de la moitié des cas, doivent faire réfléchir avant de proposer un tel acte à des hommes jeunes, supportant mal une gêne urinaire et désireux de 
poursuivre leur activité sexuelle.

Références bibliographiques :

1. S. E. LERNER, S. L. RICHARDS, A. E. BENET, N.Z. KAHAN, J. D FLEISCHMANN, A. MELMAN:

Evaluation détaillée de la fonction sexuelle après prostatectomie radicale : la satisfaction des patient est-elle corrélée à la qualité des érections? Service d'Urologie, Albert Einstein College of Medicine, Montefiore Medical Center, New York, USA.

2. P. COEURDACIER, F. STAERMAN, L. CORBEL, B. CIPOLLA, F. GUILLE, B. LOBEL : Peut-on mieux faire que la chirurgie dans le traitement de l'hypertrophie bénigne de prostate? Les résultats à 10 ans de la résection endoscopique et de l'adénomectomie sur les troubles mictionnels et la sexualité. Senvice Urologie, Centre Hospitalo-Universitaire, Rennes.

\section{POSTER 58}

Evaluation de l'apoptose par détection des caspases activées au cours de la méiose masculine chez les patients azoospermiques

\section{J.PERRIN1, C. GEOFFROY-SIRAUDIN1, J.SAIAS-MAGNAN1, B. COURBIĖRE2, G. KARSENTY3, J.M. GRILLO1, M. GUICHAOUA1, C. METZLER-GUILLEMAIN1}

1 Laboratoire de biologie de la Reproduction, CECOS, Hôpital La conception, AP-HM, Marseille, France 2 Centre de Procréation Médicalement Assistées, Hôpital La conception, AP-HM, Marseille, France 3 Senvice d'urologie, Hôpital Sainte Marguerite, AP-HM, Marseille, France Jeanne.perrin@ap-hm.fr

Introduction : Les études de la méiose chez les patients atteints d'azoospermie ont permis de montrer que les anomalies de l'appariement de type asynapsis, ainsi que la fragmentation des bivalents étaient significativement plus fréquentes dans les pathologies non obstructives que dans les pathologies obstructives. II a été suggéré que la fragmentation pouvait être liée à une apoptose des cellules méiotiques. Néanmoins, aucune étude conjointe de la méiose et de l'apoptose n'a encore été réalisée chez l'homme. Le but de notre travail est d'évaluer de degré d'activation des caspases, étape précoce du processus apoptotique, dans les cellules méiotiques chez les patients azoospermiques qui bénéficient d'une biopsie testiculaire en vue d'ICSI.

Matériel et Méthodes : Nous avons réalisé cette étude chez 3 patients âgés de 30 à 53 ans, ayant une azoospermie non obstructive et un caryotype normal. L'un des trois patients est porteur d'une délétion de la région $A Z F c$. Les biopsies testiculaires ont été réalisées chirurgicalement, puis le tissu testiculaire a été dilacéré puis traité en vue d'extraction de spermatozoïdes. Les cellules restant après traitement ont fait l'objet d'une recherche de caspases activées (kit polycaspases FLICA) suivie d'une immunocytochimie avec l'anticorps anti SCP3, protéine constitutive de l'élément axial/latéral du complexe synaptonémal (CS).

Résultats : Chez les 3 patients, $3 \%$ à $40 \%$ des cellules méiotiques analysées présentaient des d'anomalies de type asynapsis ou fragmentation des CS. Le pourcentage de cellules méiotiques caspases positives variait de $0 \%$ à $15 \%$. L'activation des caspases était présente dans $18 \%$ des cellules dont les complexes synaptonémaux présentaient des asynapsis. Parmi les cellules caspases positives, $14 \%$ présentaient la même anomalie. Jusqu'à présent, nous n'avons pas observé de cellule caspase positive avec CS fragmenté. L'extraction de spermatozoïdes a été effective pour 2 patients, négative pour le patient porteur d'une délétion AZFc.
Discussion et conclusion : A notre connaissance, cette étude est la première permettant l'évaluation de l'activation des caspases conjointement à l'étude méiotique. Les résultats préliminaires sur 3 patients montrent que le processus apoptotique peut être initié au cours de la méiose, et que la fragmentation des CS n'est pas associée à une activation des caspases. II est cependant nécessaire d'accroitre le nombre de patients étudiés et d'évaluer les étapes ultérieures du processus apoptotique, notamment la fragmentation de l'ADN.

\section{POSTER 59}

Le cheminement diagnostic dans le cadre de la mutation « Maghrebine »: à propos d'un cas

\section{N. PRISANT1, M. PRADES1, C. JOURNO1, R. HARBUZ2, P. RAY2, C. POIROT1}

1 UF de Biologie de la Reproduction et d'AMP, Groupe Hospitalier Pitié Salpêtrière, APHP, UPMC Paris VI 2 Département de Génétique et Procréation, UF de Biochimie et Génétique Moléculaire, CHU Grenoble nprisant@yahoo.com

Nous présentons le cas de Mr. M. patient de 27 ans d'origine marocaine. Ce couple consulte dans le cadre d'une infertilité primaire de 5 ans. Mme $M$. est âgée de 26 ans et ne présente aucun antécédent particulier en dehors d'une hépatite $B$ néonatale.

Le bilan : Al'interrogatoire, Mr M. n'a aucun antécédent génital, pas de cryptorchidie, pas de varicocèle, pas de hernie, n'est pas exposé aux toxiques ou à la chaleur, a été vacciné contre les oreillons. Dans ses antécédents familiaux on ne note aucune maladie génétique connue mais il signale que ses deux grands-pères étaient frères. II a 3 frères (dont un avec enfant) et 3 sœurs (dont deux avec enfants). Al'examen clinique, les deux testicules sont de taille et de consistance normales, en place dans les bourses, les déférents sont palpés à droite et à gauche. II n'y pas de varicocèle ni de hernie.

L'échographie testiculaire est normale et le caryotype montre une formule chromosomique 46,XY. Au spermogramme on retrouve une concentration de $11.10^{6}$ spermatozoïdes $/ \mathrm{mL}$, dans un éjaculat de $3,5 \mathrm{~mL}$, une vitalité à $70 \%$ et une mobilité a $0 \%$, b $5 \%$, c $5 \%$ et d $90 \%$ à la première heure, c $5 \%$ et $d 95 \%$ à la 4 ème heure. Au spermocytogramme il n'y a pas de forme typique et $74 \%$ des spermatozoïdes sont macrocéphales avec $48 \%$ des spermatozoïdes polyflagelles. L'IAM est très élevé à 3,67. Ce résultat confirme un examen précédent effectué en ville.

La démarche diagnostique : Le tableau clinico-biologique, en particulier la morphologie des spermatozoïdes, et l'origine et les antécédents familiaux de Mr M. nous amènent à suspecter la mutation du gène Aurora Kinase C (AURKC) détectée à l'état homozygote chez 14 patients d'origine Maghrébine (Dieterich et coll. 2007). Un échantillon de sang a été adressé au laboratoire de Biochimie et Génétique Moléculaire du CHU de Grenoble pour recherche de la mutation c.144delC par séquençage de l'exon 3 du gène AURKC. Mr. M. est homozygote pour cette mutation du gène AURKC. Elle entraîne un blocage des divisions meiotiques lors de la spermatogénèse expliquant le phénotype de spermatozoïdes macrocéphales polyflagelles constaté au spermocytogramme.

A ce stade, le couple souhaite continuer la prise en charge par ICSI bien qu'il leur ait été expliqué que les anomalies chromosomiques retrouvées dans les spermatozoïdes ne laissaient pas présager de la conception d'embryons viables.

Après discussion, il est décidé d'analyser le contenu chromosomique 
des spermatozoïdes de Mr M. en cytométrie de flux. Un échantillon de sperme congelé a été adressé à Grenoble pour analyse. Les résultats montrent que la totalité des spermatozoïdes de $\mathrm{Mr}$. M. contient quatre quantités d'ADN, aucun spermatozoïde haploïde n'est retrouvé.

La décision est alors prise est d'arrêter la prise en charge en AMP du couple M. qui s'oriente actuellement vers l'adoption pour réaliser leur projet parental. Une étude de la fratrie de Mr. M. est en cours de discussion.

Conclusion : Ce cas clinique illustre un des rares cas d'infertilité d'origine masculine (avec la globozoospermie), dont le diagnostic peut être effectué dès le spermocytogramme et dont l'exploration par analyse moléculaire et cytométrie de flux mène à l'arrêt rapide de prise en charge en AMP. Le couple peut ainsi, en ayant gagné du temps et sans avoir eu à engager des dépenses inutiles, se consacrer à la possibilité que leur offre l'adoption de fonder une famille.

Références bibliographiques :

1. Achard, V., Paulmyer-Lacroix, O., Mercier, G., Porcu, G., SaiasMagnan, J., Metzler-Guillemain, C. \& Guichaoua, M.R. Reproductive failure in patients with various percentages of macronuclear spermatozoa: high level of aneuploid and polyploid spermatozoa. J Androl 28, 600-6 (2007).

2. Benzacken, B., Gavelle, F.M., Martin-Pont, B., Dupuy, O., Lievre, N., Hugues, J.N. \& Wolf, J.P. Familial sperm polyploidy induced by genetic spermatogenesis failure: case report. Hum Reprod 16, 2646-51 (2001). 3. Devillard, F., Metzler-Guillemain, C., Pelletier, R., DeRobertis, C., Bergues, U., Hennebicq, S., Guichaoua, M., Sele, B. \& Rousseaux, S. Polyploidy in large-headed sperm: FISH study of three cases. Hum Reprod 17, 1292-8 (2002).

4. Dieterich K, Soto Rifo R, Faure AK, Hennebicq S, Ben Amar B, Zahi $M$, Perrin J, Martinez D, Sèle B, Jouk PS, Ohlmann T, Rousseaux S, Lunardi J, Ray PF. Homozygous mutation of AURKC yields large-headed polyploid spermatozoa and causes male infertility Nat Genet. 39, 661-5 (2007).

5. Escalier, D. Human spermatozoa with large heads and multiple flagella: a quantitative ultrastructural study of 6 cases. Biol Cell 48, 65-74 (1983).

6. Guthauser, B., Vialard, F., Dakouane, M., Izard, V., Albert, M. \& Selva, J. Chromosomal analysis of spermatozoa with normal-sized heads in two infertile patients with macrocephalic sperm head syndrome. Fertil Steril 85, 750 e5-750 e7 (2006).

7. In't Veld, P.A., Broekmans, F.J., de France, H.F., Pearson, P.L., Pieters, M.H. \& van Kooij, R.J. Intracytoplasmic sperm injection (ICSI) and chromosomally abnormal spermatozoa. Hum Reprod 12, 752-4 (1997). 8. McKusick, V.A. Infertility associated with multi-tailed spermatozoa and excessive DNA. (OMIM Online Mendelian Inheritance in man, 1986).

9. Nistal, M., Paniagua, R. \& Herruzo, A. Multi-tailed spermatozoa in a case with asthenospermia and teratospermia. Virchows Arch $B$ Cell Pathol 26, 111-8 (1977).

\section{POSTER 60}

Les prostasomes modulent-ils la capacitation des spermatozoïdes humains cryoconservés ?

\section{H. PONS-REJRAJI, S. SANFILIPPO, L. JANNY, G. GRIZARD}

Biologie de la Reproduction E.A 975, Faculté de Médecine et Service de Biologie de la Reproduction, $\mathrm{CHU}$, Clermont-Ferrand, France sanfilipposandra@hotmail.com

Introduction : La cryoconservation des spermatozoïdes (spz) est largement utilisée en Assistance Médicale à la Procréation (AMP), mais la qualité et le pouvoir fécondant des gamètes sont altérés après congélation/décongélation. Les propriétés physico-chimiques des spz fraîchement éjaculés et leur pouvoir fécondant peuvent être modulés par les prostasomes, vésicules prostatiques normalement présentes dans l'éjaculat. Le but de l'étude est d'évaluer la capacitation, événement central dans l'acquisition du pouvoir fécondant, des spz cryoconservés, et d'analyser l'effet des prostasomes sur celle-ci.

Matériel et Méthodes : Les échantillons $(n=10)$ proviennent de spermes congelés dans un milieu cryoprotecteur et conservés dans l'azote liquide.

Après décongélation, les spz sont sélectionnés sur gradient de densité (Percoll ${ }^{\circledR}$ ). Les spz contenus dans la fraction la plus dense sont incubés à une concentration de $20.106 \mathrm{spz} / \mathrm{ml}$ dans le milieu capacitant BWW $(+0,3 \% \mathrm{BSA}), 3 \mathrm{~h}$, à $37^{\circ} \mathrm{C}$, sous $5 \%$ de $\mathrm{CO}_{2}$. Des spz sont incubés sous les mêmes conditions en présence de $500 \mu \mathrm{M}$ de 3-Iso-Butyl-Methyl-Xanthine (IBMX) afin d'amplifier la voie AMPc/PKA impliquée dans la capacitation, et/ ou de 150 $\mu \mathrm{M}$ équivalent cholestérol de prostasomes. La proportion de $\mathrm{spz}$ " capacités " ou ayant effectué leur réaction acrosomique (RA) spontanée est évaluée par marquage épifluorescent à la chlortétracycline (CTC). La phosphorylation sur résidus tyrosine ( $P$-Tyr) des protéines $p 80$ et $\mathrm{p} 105$, impliquées dans la signalisation associée à la capacitation, est réalisée par Western-blot et densitométrie. L'intégrité membranaire des $\mathrm{spz}$ est évaluée après marquage à l'iodure de propidium.

Résultats : Après incubation, le pourcentage de spz « capacités » augmente significativement ( $36 \pm 4 \%$ vs $14 \pm 2 \%$ ) ainsi que la quantité de spz ayant effectué leur RA ( $22 \pm 3 \%$ vs $9 \pm 1 \%)$ sans altération de l'intégrité membranaire. Le niveau de P-Tyr est multiplié par un facteur de $9 \pm 5$ et $3 \pm 1$ respectivement pour $p 80$ et pour $p 105$. L'IBMX amplifie la $P$-Tyr de $p 80 / 105$ ( $25 \pm 17$ vs $9 \pm 5$ pour $p 80$ et $5 \pm 2$ vs $3 \pm 1$ pour p105) mais n'a pas d'effet sur le pourcentage de spz « capacités " ou ayant effectué leur RA. Les prostasomes entraînent une diminution significative du pourcentage de spz " capacités " $(19 \pm 3 \%$ vs $36 \pm 4 \%$ ) et de la $P$-Tyr de $p 80 / 105(7 \pm 4$ vs $9 \pm 5$ pour p80 et $2,0 \pm 0,5$ vs $3 \pm 1$ pour $\mathrm{p} 105)$ sans affecter l'intégrité membranaire. Le pourcentage de $\mathrm{spz}$ ayant effectué leur RA est diminué mais de façon non significative $(12 \pm 1 \%$ vs $22 \pm 3 \%$ ). Les prostasomes inhibent l'effet stimulateur de l'IBMX sur la P-Tyr des protéines p80 (6 \pm 2 vs $25 \pm 17$ ) et $p 105$ ( $4 \pm 1$ vs $5 \pm 2$ ).

Discussion et Conclusion : Dans nos conditions expérimentales, les $\mathrm{spz}$ cryoconservés capacitent de manière analogue aux spz frais. Les prostasomes affectent le remaniement membranaire et la signalisation associés à la capacitation des spz cryoconservés et leur action s'exerce, pour une part, via la voie AMPc/PKA. Une supplémentation des milieux cryoprotecteurs par des prostasomes ou des liposomes ayant les propriétés des prostasomes pourrait être envisagée pour éviter une capacitation et une RA précoces liées au processus de cryoconservation.

\section{POSTER 61}

\section{Maladie de la peyronie : résultats de 120 cas traités par la tamoxifène et le VERPAMIL}

\author{
R. Reda \\ Hôpital Alhayt, Beyrouth, Liban raefrida@hotmail.com
}

La maladie de la peyronie est caractérisée par la présence de plaques au niveau des corps caverneux du pénis ; en association d'une érection douloureuse et d'une courbure de la verge.

120 patients ont été diagnostiqués et confirmés par l'echographie 
où elle visualise la ou les plaques unies ou multiples.

Les facteurs de risque sont l'arthrite, l'hypertension, le diabète, le traumatisme de la verge.

Le traitement a été la tamoxifène par voie orale et par l'injection de VERPAMIL intra-lésionel.

La durée du traitement est de 9-12 mois.

Les résultats sont : $\quad 90 \%$ : amélioration de la douleur ;

$45 \%$ diminution de la courbure :

$40 \%$ diminution de la taille de la plaque.

\section{POSTER 62}

Hypospermie : quel bilan et pourquoi ?

G. ROBIN, F. MARCELLI, V. MITCHELL, C. MARCHETTI, L. LEMAITRE, M. LEROY-BILLIARD, D. DEWAILLY, J.M. RIGOT

Services d'Andrologie,CHRU Lillef-marcelli@chru-lille.fr

Diagnostic : Volume d'éjaculat inférieur à $2 \mathrm{ml}$ sur au moins 2 spermogrammes.

Eléments anamnestiques : recherche d'un défaut de recueil, ATCD significatifs (mucoviscidose, polypose nasale, asthme, diabète, pathologies neurologiques, chirurgie pelvienne ou lombo-aortique, infection génitale, retard pubertaire..), prise médicamenteuse, troubles de la sexualité associée.

Eléments cliniques : Dilatation épididymaire, absence de canal(s) déférents(s), gynécomastie et/ou autres signes d'hypoandrogénie.

Eléments spermiologiques : $\mathrm{pH}$ et biochimie séminale à niveau d'atteinte de l'obstruction, recherche de spermatozoïdes dans les urines.

Eléments hormonologiques : Testostérone totale et LH ; FSH si OATS associée.

Eléments d'imagerie : Echo $( \pm \mathrm{IRM})$ du carrefour prostato-vésiculodéférentiel et du haut appareil urinaire.

Eléments génétiques : recherche d'anomalies moléculaires du gêne CFTR (technique de screening par D-HPLC puis séquençage).

\section{Conclusion :}

La réalisation du bilan étiologique d'une hypospermie, se justifie car :- la plupart des causes relèvent de prises en charge spécifiques,

- la gravité potentielle de certaines d'entres elles justifie un dépistage rapide et une prise en charge spécialisée (mucoviscidose, hypogonadisme...).

La recherche des causes iatrogènes et des antécédents orientera la démarche étiologique dont le bilan paraclinique s'articule autour de l'exploration du carrefour prostato-vésiculo-déférentiel et si besoin de l'analyse du gène CFTR. Le recours au traitement de la cause de l'hypospermie sera envisagé dès que possible, s'il ne compromet pas la fertilité ultérieure.

\section{POSTER 63}

Analyse moléculaire du gène de l'aromatase et le récepteur aux estrogènes alpha chez les souris (mus musculus domesticus) robertsonienne et standard et leurs hybrides de Tunisie

\section{SAIID1, 3, C. DELALANDE3, S. BOURGUIBA4, A. SAÂD1, K. SAIID2, S. CARREAU3 \\ 1 Laboratoire de Cytogénétique et de Reproduction; Faculté de Médecine de Sousse, 2 Unité de Recherche Génétique \\ Biodiversité et Valorisation des Bioressources; Institut Supérieur de Biotechnologie de Monastir, \\ 3 Laboratoire de Biochimie, IRBA, Université de Caen, France \\ 4 Département de Physiologie, Université de Turku, Finlande lamia_said2001@yahoo.fr}

Introduction : L'accumulation de fusions Robertsoniennes chez la souris domestique Mus musculus domesticus est considérée comme un exemple illustrant le modèle de spéciation chromosomique. En effet, le croisement entre la race standard $(2 n=40)$ et la race Robertsonienne $(2 n=22)$ conduit à des hybrides chromosomiques dont la fertilité peut être profondément perturbée. Les coupes histologiques des testicules de ces hybrides montrent une réduction des tubes séminifères et un dérèglement total de la différenciation de la lignée germinale laissant présager un dérèglement génique de la fonction de reproduction à côté de la production de gamètes aneuplö̈des résultant des non-disjonctions des chromosomes au cours de l'anaphase. Il a été démontré que l'aromatase (enzyme responsable de la conversion irréversible des androgènes en estrogènes) ainsi que les récepteurs aux estrogènes jouent un rôle important dans le bon déroulement de la spermatogenèse et les fonctions testiculaires et épididymaires. Ceci nous a amené à entreprendre l'analyse des gènes de l'aromatase et du récepteur aux estrogènes alpha comme gènes candidats impliqués dans la stérilité hybride.

Matériel et Méthodes : L'analyse moléculaire a porté sur 76 souris des deux races chromosomiques $(2 n=40$ et $2 n=22)$ et de leurs hybrides. Les deux races parentales et les hybrides naturels ont été capturés dans la ville de Monastir à l'aide de pièges de type firobind. Les hybrides de première génération à $2 n=31$ ont été obtenus au laboratoire à partir de croisements inter-raciaux. Les caryotypes ont été préparés selon la technique de l' " air drying " et les chromosomes ont été identifiés par la méthode du Banding $\mathrm{G}$. L'extraction des ARN totaux a été effectuée à partir des gonades selon la méthode décrite par Chomczynski \& sacchi (1987). Après une évaluation quantitative et qualitative des l'ARN totaux, nous avons réalisé dans une première étape une transcriptase reverse pour convertir les ARNm en ADNc et dans une deuxième étape une polymérisation en chaîne semi-quantitative pour les gènes de l'aromatase et du récepteur aux estrogènes Alpha. L'actine a été prise comme un gène de ménage.

Résultats : Les résultats de RT-PCR semi-quantitative montrent que l'ARNm de l'aromatase et le récepteur aux estrogènes Alpha sont présents aussi bien dans les testicules des souris des deux races chromosomiques que dans les testicules de leurs hybrides chromosomiques.

Conclusion : Nos résultats indiquent qu'à priori, la baisse de fertilité des hybrides chromosomiques n'est pas due à une perturbation de l'expression des gènes de l'aromatase ou du récepteur aux estrogènes alpha. Toutefois, il est possible que l'ARNm aromatase décelé chez les hybrides soit traduit en une protéine inactive par suite de modifications post-traductionnelles. Une étude de l'activité de 
l'aromatase doit être menée chez les hybrides pour exclure cette éventualité dans la perturbation de leur fonction de reproduction. L'analyse d'autres marqueurs tels que les récepteurs aux estrogène ER? et les taux sériques des hormones LH, FSH, testostérone et estradiol contribuera à la compréhension des facteurs qui seraient à l'origine de la stérilité des hybrides.

\section{POSTER 64}

Relations entre les marqueurs épididymaire, prostatique et vésiculaire et la mobilité et la morphologie des

spermatozoïdes chez des hommes Tunisiens consultant pour infertilité du couple

\section{SAIID1,2, I. GALERAUD-DENIS2,3, S.CARREAU2, A. SAÂD1}

1 Service de Cytogénétique et Biologie de la Reproduction, Hôpital Universitaire Farhat Hached, Sousse, Tunisia

2 Département de Biochimie Université de Caen, France

3 Unité de Biologie de la Reproduction CHU Caen, France

$$
\text { lamia_said2001@yahoo.fr }
$$

Introduction : Le plasma séminal résulte d'un mélange des sécrétions de plusieurs glandes accessoires mâles comme l'alpha glucosidase neutre, la carnitine et la glycerolphosphocholine pour l'épididyme, l'acide citrique et le zinc pour la prostate et le fructose et la prostaglandine pour la vésicule séminale. Ces marqueurs biochimiques jouent un rôle important dans la maturation et l'acquisition de la mobilité et du pouvoir fécondant des spermatozoïdes. Dans ce travail, nous avons évalué l'implication de certains de ces paramètres biochimiques dans l'infertilité d'une population tunisienne d'hommes présentant des altérations de la mobilité et de la morphologie des spermatozoïdes.

Matériels et Méthodes : L'étude a porté sur le sperme, obtenu par masturbation après une abstinence de 3 à 5 jours, de 124 patients tunisiens consultant pour infertilité au Service de Cytogénétique et Biologie de la Reproduction à l'hôpital Farhat Hached de Sousse durant la période novembre 2005 - avril 2006 et 38 hommes témoins normospermiques. Un spermogramme et un spermocytogramme ont été réalisés pour chaque individu; les taux de fructose et d'acide citrique ont été déterminés par l'utilisation du kit Boehringer Mannheim $\mathrm{GmbH}$ et l'activité de l'alpha glucosidase neutre a été estimée en utilisant le substrat paranitrophenyl-?-D-glucopyranoside (PNPG). Le logiciel SPSS 9 a servi pour l'analyse statistique.

Résultats : Les patients asthénozoospermiques montrent une diminution significative du taux de fructose par rapport aux asthénotératozoospermiques $(p=0,04)$. L'alpha glucosidase neutre et l'acide citrique ne montrent aucune différence significative entre les différents groupes. L'analyse de corrélation montre que l'alpha glucosidase neutre est corrélée positivement avec le volume séminal $(r=0,517, p<0,001)$ et le $\mathrm{pH}(r=0,280, p<0,001)$, le fructose est corrélé positivement avec le volume séminal $(r=0,249, p<0,006)$ et négativement avec la numération des spermatozoïdes ( $r=-0,205$, $\mathrm{p}<0,023$ ) et l'acide citrique est corrélé négativement avec le pH ( $\mathrm{r}=-$ $0,565, p<0,001$ ). De plus, nous avons mis en évidence une corrélation positive entre le taux de fructose et la morphologie des spermatozoïdes surtout pour les restes cytoplasmiques $(r=0,219$, $p=0,015)$ et restes cytoplasmiques sans flagelle $(r=0,2, p=0,027)$.

Conclusion : Notre étude montre qu'il existe une relation complexe entre le fructose et les paramètres cytologiques et morphologiques des spermatozoïdes. Elle indique aussi que l'alpha glucosidase et l'acide citrique constituent des déterminants significatifs seulement pour les paramètres cytologiques. Ces données montrent que le fructose est un marqueur séminal aussi important que l'alpha glucosidase et l'acide citrique chez les hommes stériles et une attention particulière doit être donnée à ce marqueur chez les asthénozoospermiques et les asthénotératozoospermiques dans la recherche thérapeutique.

\section{POSTER 65}

\section{Spermocytogramme haute résolution en temps réel sur spermatozoïdes mobiles}

\section{R. SAIDI, E. GRUEL, M.H. CHELLLI, S. MAZURIER, J. BLESSMAN-ROSET, N. MOUSSET-SIMÉON, S.MENON, B. MACÉ, N. RIVES}

Laboratoire de Biologie de la Reproduction - CECOS, EA 4308 "Spermatogenèse et Qualité du gamète mâle", CHU Hôpitaux de Rouen, 76031 Rouen nathalie.rives@chu-rouen.fr

Introduction : L'examen du sperme tel défini par l'OMS constitue une des étapes clefs dans I?exploration du couple infertile. La morphologie du spermatozoïde (spz) a été reconnue comme le meilleur facteur prédictif de la fertilité naturelle, de l?issue en insémination intrautérine ou en fécondation in vitro classique. Les anomalies ultrastructurales des spz qui sembleraient être les seules anomalies capables d'influencer le devenir de l'ICSI ne sont pas détectables aux grossissements $100^{\prime}$ ou 200-400' utilisés au cours de la procédure d'ICSI. Bartoov et al. (2002) a mis au point un système capable d'étudier la morphologie fine des spz mobiles en temps réel au grossissement $6600^{\circ}$ appelé MSOME pour "Magnification Motile Sperm Morphology Examination". Les anomalies détectées à ce grossissement, en dehors des anomalies morphologiques habituelles, sont des vacuoles situées sur les têtes spermatiques dont la localisation, le nombre et la taille sont variables. Même si Bartoov et al. ont essayé de définir une valeur normale du pourcentage de vacuoles, ces normes ne sont pas d'emblée applicables dans une évaluation diagnostique. L'objectif de notre travail a été d'établir un spermocytogramme "MSOME" afin de définir des seuils de normalité et d'évaluer les différences observées entre deux populations d'hommes, l'une aux paramètres spermatiques normaux (groupe $T, n=50$ ) et l'autre aux paramètres spermatiques altérés (groupe $P, n=53$ ).

Matériel et méthodes : Une étude prospective a été conduite chez 103 hommes $(P+T)$ consultant pour la réalisation d'un spermogramme dans le Laboratoire de Biologie de la Reproduction du $\mathrm{CHU}$ de Rouen entre Novembre 2006 et Mars 2007. Dans un deuxième temps, ces hommes ont été répartis en deux groupes "Fertiles" et "Infertiles", tenant compte de l'existence ou non d'une naissance vivante antérieure obtenue spontanément ou après assistance médicale à la procréation. Tous les sujets̀ ont bénéficié d'un spermogramme et d'une étude morphologique en MSOME sur sperme éjaculé frais. Les spz évalués au grossissement $6600^{\circ}$ sont classés en fonction de la morphologie conventionnelle et selon la présence, le nombre et la taille des vacuoles par rapport à la surface de la tête spermatique. Soixante quinze spz mobiles sont observés au microscope au grossissement $6600^{\prime}$ sans aucune mesure précise. Les spz sont classés selon leur normalité et les paramètres des vacuoles définis ci-dessous. Vingt-cinq $\mathbf{s p z}$ sont photographiés individuellement et des mesures précises sont réalisées l'aide d'un logiciel spécial (IMâ 100, Leica, Allemagne), la longueur, la largeur et la surface de la tête sont mesurées ainsi que la surface vacuolaire. Les spz sont alors classés en quatre catégories tenant compte du 
nombre de vacuoles, de la surface vacuolaire par rapport à la surface de la tête : Type 0 : Spz sans vacuole; Type I: Spz avec une seule vacuole couvrant $10 ; 4]$ \% de la surface de la tête; Type II : Spz avec une seule vacuole couvrant $14 ; 16]$ \% de la surface de la tête ou au moins 2 vacuoles couvrant ]0;16] \% de la surface de la tête; Type III : 1 ou plusieurs vacuoles occupant plus de $16 \%$ de la surface de la tête.

Résultats : La surface vacuolaire est plus importante chez les $\mathrm{P}$ alors que le nombre moyen de vacuoles est plus faible par comparaison au T. Dans le groupe T, les spz de type I (30\%) et de type II (48\%) sont les plus fréquemment observés. Dans le groupe $\mathrm{P}$, la majorité des spz étaient de type II $(54 \%)$ et de type III (29\%). Les sujets fertiles ont un taux significativement plus important de spz avec des surfaces vacuolaires inférieurs à $4 \%(p=0.03)$ et le nombre moyen de vacuoles est plus élevé ( 2.43 vs $4.85, p<0.001$ ). Les sujets infertiles ont une proportion significativement plus importante de $\mathrm{spz}$ ayant des surfaces vacuolaires dépassant $16 \%$ ( $23 \%$ vs $15 \%$, $\mathrm{p}=0.007$ ).

Conclusion : Les anomalies observées en MSOME sont corrélées aux altérations des paramètres spermatiques conventionnels. Cette analyse peut avoir un caractère prédictif du "pouvoir fécondant" des spermatozoïdes en reproduction naturelle ou assistée. Le spermocytogramme MSOME est un préalable dans l'exploration des altérations spermatiques sévères avant ICSI qui sera classique ou précédée d'une sélection morphologique fine des spermatozoïdes avant injection si les spz sont essentiellement de types II et III.

\section{POSTER 66}

\section{Pseudohermaphrodisme masculin : étude clinique et} orientation génétique à propos d'un cas clinique

\section{SLIM, M. CHADLI-CHAIEB, S. TRIMECH-AJMI, A. MAAROUFI-BEIZIG, K. ACH, L. CHAIEB}

Service d'endocrinologie du Professeur L. Chaieb, CHU Farhat Hached, Sousse (Tunisie) ines.slim@yahoo.fr

Introduction : Les pseudohermaphrodismes masculins ou récemment appelés $46, \mathrm{XY}$ DSD (disorders of sex development) correspondent à une insuffisance plus ou moins complète de masculinisation des organes génitaux externes pendant la période fœtale. Le syndrome d'insensibilité aux androgènes représente de loin l'étiologie la plus fréquente, mais d'autres étiologies plus rares telles qu'une anomalie de détermination testiculaire ou un trouble de l'hormonosynthèse de la testostérone peuvent être également en cause. Dans ces derniers cas la biologie moléculaire est d'un grand apport pour le diagnostic étiologique et le conseil génétique.

Observation : Nous rapportons ici le cas d'une jeune fille âgée de 16 ans consultant pour aménorrhée primaire. Elle n'a pas de fratrie et son père est décédé suite à un cancer bronchique. Elle n'a pas d'antécédent de perte de sel en période néonatale ni de retard mental. L'examen physique a montré une absence de syndrome dysmorphique avec des organes génitaux externes de type féminin sans ambiguïté (Stade 6/7 de Quigley), un vagin borgne et une absence totale de pilosité. Aucune masse évoquant des gonades au niveau des plis inguinaux ou des grandes lèvres n'a été retrouvée. Le Caryotype était 46, XY. Une insensibilité complète aux androgènes était donc fortement suspectée. Cependant, la testostéronémie de base était effondrée $(0,25 \mathrm{ng} / \mathrm{ml})$ ne répondant pas à la stimulation par hCG. Le taux de LH était normal. La cœlioscopie exploratrice n'a pu mettre en évidence de dérivés müllériens ni de gonades. L'imagerie a objectivé par ailleurs un rein en fer à cheval.

Discussion : il s'agit d'une pathologie très rare ne rentrant pas dans le cadre du syndrome d'insensibilité aux androgènes. L'absence d'insuffisance surrénalienne à la naissance fait suspecter un trouble de l'hormonogenèse spécifique aux testicules mais le test à l'hCG n'a pas montré d'élévation de la delta4androstènedione. Une anomalie génétique survenue aux étapes précoce de la cascade de détermination testiculaire reste la plus probable devant l'absence de dérivées mûlleriens et l'anomalie rénale associée (étude génétique des gènes de SRY et WT1 étant en cours). Une prise en charge psychosociale appropriée est également nécessaire dans ce cadre.

\section{POSTER 67}

Interactions entre la voie LXR et le perturbateur endocrinien diéthylstilbestrol (DES) dans le contrôle de la fonction testiculaire de souris

\section{E. VIENNOIS1,2,3, G. ALVES1,2,3, S. BARON1,2,3, B. SION4, J.M. A. LOBACCARO1,2,3,F. CAIRA1,2,3}

1 Unité GReD, Clermont Université ; 2 UMR CNRS 6247

INSERM U931; 3 Centre de Recherche en Nutrition Humaine ; 24 avenue des Landais, 63177 Aubière Cedex ; 4 EA975 Université d'Auvergne, 63000 Clermont-Ferrand, France emilie.viennois@orange.fr

L'exposition accidentelle à des perturbateurs endocriniens environnementaux (PEE), tels que certains pesticides, herbicides et/ou fongicides, peut conduire à une cryptorchidie et/ou une oligospermie liées à une apoptose chronique des cellules germinales et ainsi à une diminution de la fertilité chez l'homme. Un des mécanismes d'action de ces PEE est l'interaction avec le système endocrinien ainsi que l'altération du métabolisme du cholestérol dont un des acteurs majeurs reste les récepteurs nucléaires des oxystérols, LXRa et b. Les LXR sont exprimés dans le testicule où ils ont un rôle fondamental dans le maintien de la fonction de reproduction par le contrôle de la stéroïdogenèse, de l'homéostasie du cholestérol et des acides gras et de la balance prolifération/apoptose des cellules germinales. Ainsi, les souris déficientes en LXR (lxr- $/$-) présentent un niveau plus faible de testostérone testiculaire, une accumulation anormale de lipides dans les cellules de Sertoli et les spermatocytes, et développent une stérilité secondaire dès l'âge de 5 mois suite à la perte des cellules germinales. Ces observations suggèrent l'existence d'une interaction entre les voies de signalisation régulées par les $L X R$ et celles altérées par les PEE.

Afin d'étudier cette hypothèse, des souris sauvages ou Ixrab-/- ont été traitées (injection s.c.) par $5 \mu \mathrm{g}$ de diéthylstylbestrol (DES), perturbateur endocrinien à activité oestrogénique et antiandrogénique, ou $25 \mu \mathrm{l}$ d'excipient (huile d'arachide) de $\mathrm{J} 1$ à $\mathrm{J} 5$ post partum ( $\mathrm{N}=25$ animaux par groupe). A trois mois les souris ont été sacrifiées et les testicules prélevés. L'analyse histologique des testicules des quatre groupes d'animaux a été réalisée par des colorations hématoxyline-éosine-safran (structure) ou avec l'huile rouge (coloration des lipides neutres). Le marquage du PCNA a été utilisé pour quantifier la prolifération. Les différentes fractions lipidiques testiculaires ont été identifiées et quantifiées après extraction par chromatographie sur couche mince. Les différentes accumulations d'ARN ont été mesurées par PCR quantitative. Les taux d'androgènes ont été mesurés dans le plasma. 
Nous montrons pour la première fois que l'administration néonatale de DES provoque une diminution significative des taux de phosphatidyl-éthanolamine (PdtEth) et de phosphatidyl-choline (PdtCho) membranaires, chez la souris sauvages, deux lipides membranaires impliqués dans les processus de survie cellulaire. De façon intéressante, ces diminutions de PdtCho et PdtEth sont observées dans les souris Ixrab-/- non traitées par le DES. De plus, le DES ne modifie pas la prolifération cellulaire du testicule de souris sauvages alors qu'en absence de LXR, le DES entraîne une augmentation significative de la prolifération.

Au final ces résultats montrent pour la première fois l'existence d'interactions entre les voies de signalisation activées par $L X R$ et celles perturbées par le DES. L'analyse des acteurs moléculaires mis en jeux (gènes cibles) est en cours. Ces données ouvrent des perspectives intéressantes quant à l'utilisation d'agoniste synthétique des LXR dans le traitement de certaines oligospermies.

\section{POSTER 68}

\section{Description des hommes ayant consulté pour infécondité entre 2000 et 2004 au Centre de Stérilité Masculine de Midi- Pyrénées, France}

\section{WALSCHAERTS1, R. MIEUSSET1, L. BUJAN1, J. PARINAUD2, P. THONNEAU1}

1 Équipe de Recherche en Fertilité Humaine (EA 3694), Hôpital Paule de Viguier, 330 avenue de Grande Bretagne, TSA 70034, 31059 Toulouse 2 Hôpital Paule de Viguier, Assistance Médicale à la Procréation, 31059 Toulouse walschaerts.m@chu-toulouse.fr

Introduction : La capacité pour un couple à avoir un enfant est une préoccupation majeure des individus et un élément important de la santé des populations. En France, un couple sur sept consultera au cours de sa vie reproductive pour des difficultés à concevoir avec une responsabilité partagée entre l'homme et la femme, le versant féminin ayant été largement plus étudié que celui de l'homme. A ce jour, très peu d'études ont décrit cette population d'hommes consultant pour infécondité. L'objectif de ce travail est d'analyser les différents parcours thérapeutiques d'hommes consultant pour infécondité, de décrire leurs parcours cliniques et biologiques, leur suivi versus abandon des procédures, le résultat en terme de grossesse. Ici, nous présenterons l'aspect méthodologique avec ses diverses contraintes ainsi que les premiers résultats descriptifs.

Matériel et Méthodes : Les données sont issues du Centre de Stérilité Masculine et du Centre d'Assistance Médicale à la Procréation de Midi-Pyrénées, France. Sur les 3155 patients venus consulter entre 2000 et 2004, $2152(68 \%)$ ont été examinés dans le cadre d'une infécondité masculine. Un questionnaire standardisé ainsi qu'un examen clinique ont été administrés à chaque patient. Le questionnaire comprend un chapitre sur son histoire reproductive, sa sexualité, ses antécédents médicaux et familiaux de l'homme et ses expositions environnementales et professionnelles. L'examen clinique décrit l'appareil reproducteur masculin : testicules, épididymes, déférents, existence ou non d'un hydrocèle ou d'une varicocèle. Nous avons décrit et comparé cette population d'hommes selon leurs antécédents et leur examen clinique selon 3 niveaux de participation : les répondants, les non répondants et les perdus de vue.

Résultats : La collection des données se terminant courant septembre, ce poster sera actualisé d'ici le congrès.
Les hommes avaient en moyenne 34 ans (écart-type $=6$ ) lors de la première consultation. L'IMC moyen est de 24 (écart-type $=4$ ). Sur les 2152 patients venus consulter entre 2000 et $2004,17 \%$ venaient pour infécondité secondaire. Concernant les antécédents médicaux, $14 \%$ des hommes ont eu une cryptorchidie, $5 \%$ un antécédent de traumatisme scrotal, $6 \%$ un antécédent de hernie inguinale. Concernant l'examen clinique, $21 \%$ étaient atteints d'une varicocèle et $4 \%$ d'une hydrocèle.

Sur les $19 \%$ des hommes étant exposés à des produits environnementaux et/ou professionnels, $15 \%$ ont été exposés à des pesticides/insecticides et $39 \%$ à des produits toxiques.

\section{POSTER 69}

Risque en AMP lorsque l'homme est HIV, HVC ou HVB positif

\author{
M.A. ZAKRAOUI, G. BOULAHIA, D. ZGHAL, S. MAHJOUB, \\ W.B. LIMAM, R. HMID, F. ZOUARI \\ Service de gynécologie et obstétrique " C "_CMNT \\ dorrazeghal@yahoo.fr
}

Problématique : Le virus d'immunodéficience acquise, les virus des hépatites $\mathrm{B}$ et $\mathrm{C}$, sont présents dans les sécrétions génitales masculines ou féminines et peuvent être transmis par voie sexuelle. Du fait de la gravité des infections dont ils sont responsables, ces virus conduisent à s'interroger sur le risque de leur transmission à l'occasion d'un acte d'assistance médicale à la procréation.

But du travail : A travers une revue de la littérature nous avons essayé de déterminer la fréquence et le niveau de détection de ces virus dans le sperme et dans les éléments prélevés avec les ovocytes à l'occasion d'une fécondation in vitro, d'évaluer le risque de transmission du virus d'immunodéficience acquise à l'occasion d'une fécondation in vitro chez un couple dont les membres sont sérodifférents et le risque nosocomial lié à la manipulation de gamètes infectés par les virus des hépatites et du VIH et de préciser les moyens permettant de maîtriser tous ces risques viraux.

Méthodes : Revue de la littérature

Discussion : Lorsque l'homme est porteur du virus d'immunodéficience acquise, les techniques de préparation et de validation virologique du sperme couplées à l'assistance médicale à la procréation permettent, si ce n'est d'annuler, du moins de porter à un niveau extrêmement faible les risques de contamination de la conjointe et par là même de l'enfant.

Pour les couples sérodifférents pour le virus de l'hépatite $C$, le problème posé n'est pas celui de la contamination sexuelle intraconjugale, et les techniques d'AMP sont donc réservées aux couples infertiles. Enfin dans le cadre de l'hépatite $B$ la vaccination de la femme quand le conjoint est infecté permet d'éviter le risque de transmission intraconjugual et par conséquent vertical. Dans tous les cas, La mise en place du circuit viral avec séparation dans le temps ou dans l'espace des activités d'AMP permet d'éviter le risque de contamination viral. Lorsque la femme est porteuse du virus de l'hépatite $\mathrm{C}$, le couple doit être clairement informé des risques de contamination non négligeables de l'enfant.

Conclusion : La prise en considération du risque viral doit faire partie intégrante des actes d'AMP. Ce risque non négligeable intéressant aussi bien les professionnels de la santé que les couples eux même exige qu'il y'est des recommandations bien définies qui prônent le respect des règles de sécurité et édictent des démarches clairement établies pour une meilleure prise en charge des couples infectés dont le désir d'enfant est tout à fait légitime. 


\section{POSTER 70}

Etude de la fragmentation et de l'oxydation de l'ADN spermatique avant et après cryoconservation du sperme chez l'homme infertile

\section{N. ZRIBI1, N. CHAKROUN FEKI1, H. ELEUCH2, R. GDOURA3, A. SELLAMI1, A. BAHLOUL4, A. HAMMAMI3, J. GARGOURI2, T. REBAI1, L. KESKES AMMAR1}

1 Laboratoire d'Histologie Embryologie, Faculté de Médecine de Sfax 2 Centre de Transfusion sanguine de Sfax 3 Laboratoire de Microbiologie, Faculté de Médecine de Sfax 4 Unité de recherche Infertilité Masculine, UR00SP11 zrnacira@yahoo.fr Ikeskes@yahoo.fr

Introduction : La maîtrise des techniques de congélation du sperme offre la possibilité d'une préservation de la fertilité masculine dans de nombreuses situations pouvant induire un risque d'hypofertilité ou même d'infertilité (traitement chirurgical, radiothérapie, chimiothérapie...). Néanmoins, la congélation provoque des altérations diverses des spermatozoïdes au niveau membranaire, morphologique mais aussi nucléaire. Les dommages de I'ADN spermatique induits par la congélation comme la fragmentation et l'oxydation pourraient être associés à un stress oxydant. L'objectif de ce travail était d'évaluer l'effet de la cryoconservation sur l'intégrité de L'ADN spermatique chez les hommes infertiles par l'étude de la fragmentation et de l'oxydation de l'ADN.

Matériel et Méthodes : L'étude a porté sur 15 échantillons de sperme appartenant à 15 hommes consultants pour infertilité du couple au laboratoire d'histologie embryologie de la Faculté de Médecine de Sfax. Les spermes ont été collectés par masturbation après un délai d'abstinence de 3 à 5 jours. Après l'analyse des paramètres spermatiques (mobilité, vitalité, morphologie, numération des spermatozoïdes et numération leucocytaire), les spermes ont été congelés dans l'azote liquide selon un protocole utilisant un cryoprotecteur commercialisé (SpermFreezeß) et durant une période de 7 à 10 jours. Après décongélation, la mobilité et la vitalité ont été également déterminées selon la méthode recommandée par l'OMS. L'étude de l'intégrité de l'ADN a été effectuée par un cytométrie de flux. Nous avons utilisé la technique TUNEL pour l'étude de la fragmentation et le kit oxy DNA assay pour la détection de la 8oxoguanine (bio marqueur du stress oxydatif) avant et après cryoconservation.

Résultats : Nous avons trouvé que la cryoconservation a provoqué une chute significative de la mobilité et de la vitalité $(45 \pm 7 \%$ vs $30.6 \pm 12.2 \% ; p=0.001$ et $77.2 \pm 8.9$ VS $45.6 \pm 8.9 ; p=0.001$, respectivement). Par ailleurs les taux de fragmentation et d'oxydation de l'ADN spermatique ont significativement augmenté après congélation $(21.3 \pm 13.7$ vs $33.1 \pm 16.6 \% ; p=0.002$ et $14.5 \pm 6.2$ vs $16.3 \pm 5.5 \% ; p=0.04$ respectivement).

Discussion et conclusion : Les résultats de cette présente étude sont en accord vec ceux rapportés dans plusieurs autres ètudes qui ont montré une altération de la mobilité et de la quantité de l'ADN spermatique après congélation/décongélation du sperme, probablement due à la création d'un état de stress oxydant et/ou à une induction de l'apoptose. Ils confirment donc l'effet délétère de la congélation sur les spermes d'hommes infertiles et incitent l'amélioration des milieux et des protocoles de congélation du sperme dans le cadre de la procréation médicalement assistée et de la préservation de la fertilité chez les hommes exposés à une radio ou chimiothérapie stérilisante.

\section{POSTER 71}

Prise en charge du mari porteur du virus d'HIV en cas d'assistance médicale à la procréation

\section{H. RAHOUEJ, D. CHELLI, F. BOUDAYA, N. HAMMEDI, B. ZAOUI, E. SFAR, H. CHELLI, M.B. CHANNOUFI}

Service de gynécologie et d'obstetrique « $A$ »-CMNT-Tunis

Avant la première tentative d'AMP il est nécessaire de rechercher les marqueurs d'infectivite par les virus d'immunodéficience humaine (VIH) 1 et 2 chez les deux membres du couple. Actuellement la séropositivité virale n'est plus une entrave à la prise en charge AMP intraconjugale.

En cas de séropositivité HIV1 chez le mari, le candidat à une AMP est celui porteur d'une charge virale dans le plasma séminal inférieur à 10000 copies par $\mathrm{ml}$, sans pathologies évolutives et leur taux de CD4 est supérieur à $200 / \mathrm{ml}$ à 2 reprises et à 4 mois d'intervalle avant l'AMP, et la femme, séronégative dans les 2 mois avant la demande doit avoir une surveillance virologique 15 jours avant l'AMP puis après 3 semaines, suivi d'un contrôle sérologique dans 3 mois puis 6 mois.

Le sperme est traité par 2 techniques successives : gradient de densité puis migration ascendante. Puis les spermatozoïdes sont récupérés et congelés dans des paillettes de haute sécurité virale. La recherche de l'ADN viral dans des paillettes, doit être négative pour une utilisation en AMP.

Toutes les techniques d'AMP peuvent être utilisées si la charge virale initiale est inférieure à 1000 copies par $\mathrm{ml}$, par contre si cette dernière est supérieure à 1000 copies par $\mathrm{ml}$ une ICSI sera faite.

Lorsque l'homme est porteur du VIH, les techniques de préparation et de validation virologique du sperme couplées à l'AMP permettent de porter à un niveau extrêmement faible les risques de contamination de la conjointe et de l'enfant.

\section{POSTER 72}

Quelles sont les causes d'échec de l'ICSI ? Point de vue du clinicien

\section{M.Z. KEDOUS, D. CHELLI, F. BOUDAYA, J. OTHMAN, B. ZOAOUI, E. SFAR H. CHELLL, M.B. CHANNOUFI}

Service de gynécologie et d'obstétrique « $A$ »-CMNT-Tunis

Introduction : II est clair que l'ICSI, représente une révolution dans la prise en charge de l'infertilité masculine. Cependant, le taux de grossesse par transfert ne dépasse pas les 25- $30 \%$ malgré les progrès scientifiques et technologiques. Les échecs de cette méthode peuvent avoir un impact psychologique et économique sérieux sur les couples stériles.

Objectif : Mettre en évidence à travers une revue de la littérature les différentes causes pouvant expliquer les échecs d'ICSI.

Résultats : L'âge de la femme est considéré comme un facteur important d'échec d'ICSI. En effet, au delà de 38 ans, le taux de succès chute au $1 / 3$. Le 2 ème facteur pronostique est le surpoids et l'obésité 
féminines qui sont significativement impliqués dans le taux d'échec de l'ICSI.

En outre, la majorité des études concluent qu'au-delà d'une valeur seuil de FSH de 9 à $10 \mathrm{UI} / \mathrm{l}$, le taux d'échec passe de $75 \%$ à $90-95 \%$. Cependant et d'après les études, le taux d'E2 n'aurait pas un impact sur le taux d'échec de l'ICSI.

Par ailleurs, une épaisseur d'endomètre $<12 \mathrm{~mm}$ augmente le taux d'échec par trois. Cependant, en ce qui concerne les paramètres spermatiques, le nombre, la mobilité ou l'origine du sperme (éjaculé ou testiculaire) ne semblent pas influencer le taux d'échec d'ICSI, mise à part la globozoospermie qui affecte sérieusement les chances de succès d'ICSI.

Conclusion : L'âge de la femme et son BMI sont considérés par tous comme des facteurs pronostiques majeurs. La valeur de la FSH peut être utile dans la prédiction des résultats de l'ICSI, celle de l'E2 est sans intérêt. L'épaisseur de l'endomètre le jour du déclenchement est intéressante. Les paramètres spermatiques ne semblent pas affecter le pronostic.

\section{POSTER 73}

Quelles sont les chances de l'homme fumeur en FIV/ICSI ?

\section{M.Z. KEDOUS, F. BOUDAYA, D. CHELLI, W. IDIR, B. ZOAOUI, E. SFAR,H. CHELLI, M.B. CHANNOUFI}

Service de gynécologie et d'obstétrique « $A$ »-CMNT-Tunis

Le tabagisme de l'un ou des deux partenaires peut compromettre les résultats de la FIV et également jouer un rôle dans le taux de succès de l'ICSI. En effet, le taux succès de l'ICSI chez les femmes ayant un partenaire tabagique est aux alentours de $22 \%$ alors qu'il passe à $38 \%$ lorsque l'homme ne fume pas. Des résultats semblables ont été observés au cours des FIV où le taux de succès grimpe de $18 \%$ à $32 \%$. Plusieurs études ont démontré que, outre l'âge de la femme et le nombre d'embryons transférés, le tabagisme masculin faisait partie des facteurs prédictifs de l'issue de l'ICSI, par ailleurs le nombre de grossesses cliniques après FIV était aussi dépendant du tabagisme chez l'homme. Le tabagisme féminin peut avoir une influence sur le nombre des ovocytes et leur capacité de fécondation en FIV, mais par contre il n'aurait pas d'impact péjoratif sur l'issue de I'ICSI. Le odds ratio des échecs d'ICSI des hommes fumeurs vs hommes non fumeurs est de 2,95 (2.65pour la FIV).

Nous concluons que le tabagisme masculin affecte le taux de succès des techniques de PMA et ce, non seulement dans les FIV, mais encore au cours des ICSI ; et mise à part les effets néfastes sur la fécondation, il pourrait altérer l'ADN des spermatozoïdes entravant ainsi le bon développement embryonnaire.

Résultats : Nous avons trouvé que la cryoconservation a provoqué une chute significative de la mobilité et de la vitalité $(45 \pm 7 \%$ vs $30.6 \pm 12.2 \% ; p=0.001$ et $77.2 \pm 8.9$ vs $45.6 \pm 8.9 ; p=0.001$, respectivement). Par ailleurs, les taux de fragmentation et d'oxydation de l'ADN spermatique ont significativement augmenté après congélation $(21.3 \pm 13.7$ vs $33.1 \pm 16.6 \% ; p=0.002$ et $14.5 \pm 6.2$ vs $16.3 \pm 5.5 \% ; p=0.04$ respectivement).

Discussion et conclusion : Les résultats de cette présente étude sont on accord avec ceux rapportés dans plusieurs autres études qui ont montré une altération de la mobilité et de la qualité de l'ADN spermatique après congélation/décongélation du sperme, probablement due à la création d'un état de stress oxydant et/ou ou à une induction de l'apoptose. lls confirment donc l'effet délétère de la congélation sur les spermes d'hommes infertiles et incitent l'amélioration des milieux et des protocoles de congélation du sperme dans le cadre de la procréation médicalement assistée et de la préservation de la fertilité chez les hommes exposés à une radio ou chimiothérapie stérilisante.

\section{POSTER 74}

Amélioration de la qualité du sperme et obtention d'une grossesse spontanée chez un patient épileptique infertile oligo-asthéno-tératospermique sévère après suppression de l'acide valproique (Dépakine®)

\section{A. BEN HAMIDA SELLAMI1,5, N. FEKI CHAKROUN1,5, B. BEN AYED2, N. ABID1, S. HAMMAMI3, I. FEKI4 ; M. GUERMAZI2, A. BAHLOUL5; T. REBAI1; L. KESKES AMMAR1,5 \\ 1 Laboratoire d'Histologie et Biologie de la Reproduction, Faculté de Médecine de Sfax \\ 2 Service de Gynécologie Obstétrique, CHU Hédi Chaker, Sfax 3 Laboratoire de pharmacologie, Faculté de Médecine Sfax \\ 4 Service de Neurologie, CHU Habib Bourguiba, Sfax \\ 5 Unité de recherche"infertilité masculine " $\mathrm{CHU}$ Habib Bourguiba,} Sfax Tunisie sellamiafifa@yahoo.fr

Introduction : Le rôle délétère de l'acide valproique (Depakine®) sur la qualité du sperme a été évoqué dans de nombreuses observations récentes qui ont révélé que l'exposition chronique à ce type de traitement anti convulsivant peut entrainer des troubles endocriniens assez importants et ont insisté sur l'effet direct de ce medicament sur les spermatozoides et leurs capacités fonctionnelles. La reduction de la fertilité des patients épileptiques traités par l'acide valproique est discutée. Nous rapportons dans ce travail l'observation d'une amelioration de la qualité du sperme et l'obtention d'une grossesse spontanée après suppression de l'acide valproique chez un patient épileptique infertile et présentant une oligoasthénotératospermie sévère.

Materiel et Méthodes : Notre observation est à propos d'un patient infertile agé de 35 ans traité pour une épilepsie par l'acide valproique (VA) pendant une periode de 25 ans et présentant une infertilité primaire de 5 ans. L'analyse répétée des paramètres spermatiques a mis en evidence une oligo-astheno-teratospermie (OAT) sévère avec un faible volume de l'éjaculat $(<2 \mathrm{ml})$, une numeration spermatique $<100,000$ spermatozoides $/ \mathrm{ml}$, une mobilité totale $<10 \%$ et une perturbation sévère de la morphologie spermatique (1\%). Le dosage plasmatique des gonadotrophines (FSH) était normal. L'exploration de la partenaire feminine était normale. Au cours de l'exploration de l'infertilité de ce couple, l'implication de l'acide valproique dans l'altération de la qualité spermatique a été suspectée et le VA a été progressivement remplacé par la Carbamazepine (Tegretolß) ; un contrôle répété des paramètres spermatiques a été realisé au cours de la période du nouveau traitement.

Résultats : Après trois mois de traitement par la Carbamazepine, le spermogramme a montré une amélioration significative des paramètres spermatiques avec une augmentation significative de la concentration en spermatozoides (16 millions spermatozoides $/ \mathrm{ml}$ ), de la mobilité totale $(40 \%)$ et une légère diminution de la tératospermie (4\%). Cette amelioration a été suivie par la survenue d'une grossesse spontanée après sept mois de la suppression de VA. Le contrôle des paramètres spermatiques après 16 mois de l'arrêt de VA a montré une augmentation du volume de l'éjaculat $(2,9 \mathrm{ml})$, une numération spermatique à 82 millions spermatozoides $/ \mathrm{ml}$, une mobilité totale à $40 \%$ (avec une augmentation nette de la mobilité progressive et 
rapide de type "a"), le taux de spermatozoides à morphologie typique était de $6 \%$.

Discussion et Conclusions : Cette observation confirme l'effet délétère de l'acide valproique sur la qualité du sperme et nous amène à suggérer que l'altération des paramètres spermatiques est liée probablement à des desordres endocriniens du sytème de contrôle de la reproduction. II a été également montré qu'une amélioration de la qualité du sperme et éventuellement un rétablissement de la fécondance des spermatozoides peuvent être obtenus par la suppression de l'acide valproique.

\section{POSTER 75}

L'infertilité secondaire masculine : caractéristiques spermatiques et étiologies

\section{A. BEN HAMIDA SELLAMI1,3, N. FEKI CHAKROUN1,3, B. BEN AYED2, N. ABID1, M. GUERMAZI2, A. BAHLOUL3, T. REBAI1, L. KESKES AMMAR1,3}

1 Laboratoire d'Histologie et Biologie de la Reproduction, Faculté de Médecine de Sfax

2 Service de Gynécologie Obstétrique, CHU Hédi Chaker, Sfax

3 Unité de recherche"infertilité masculine "CHU Habib Bourguiba, Sfax Tunisie sellamiafifa@yahoo.fr

Introduction : L'infertilité secondaire masculine est définie comme l'incapacité de concevoir chez un patient ayant déjà eu une grossesse avec sa partenaire actuelle sans tenir compte de l'issue de cette grossesse. Les études qui rapportent les facteurs étiologiques de ce trouble de la fertilité masculine sont peu nombreuses. L'objectif de ce travail était d'analyser les caractéristiques cliniques et biologiques chez ces hommes infertiles et d'établir les origines de cette perturbation secondaire de la reproduction.

Matériel et Méthodes : II s'agit d'une étude rétrospective portant sur 48 hommes infertiles sélectionnés à partir de 73 couples explorés au cours d'une période d'une année (2007) pour infertilité secondaire. Pour ces patients, nous avons analysé les données des dossiers cliniques et des explorations paracliniques (spermogramme selon les normes de l'OMS, spermoculture, échographie du tractus urogénital). Nous avons fait une analyse descriptive des données à l'aide d'un logiciel SPSS 11.0.

Résultats : Trois types d'anomalies spermatiques ont été identifiés : une oligoasthénotératospermie (OAT) chez 12 patients $(25 \%)$, une asthénospermie (A) ou une asthénotératospermie (AT) chez 18 patients $(37.5 \%)$ et une tératospermie isolée $(T)$ chez 18 patients $(37.5 \%)$. Des antécédents d'avortements spontanés étaient notés chez environ la moitié (44.4\%) des patients du groupe A et AT (vs $25 \%$ dans le groupe OAT, $p=0.2$ ). Dans le groupe OAT, le délai nécessaire à concevoir dans les grossesses antérieures était prolongé ( $>$ une année) chez $25 \%$ des couples (vs $16.6 \%$ dans le groupe (A) et (AT), $p=0.4)$. Une infection/inflammation génitale a été diagnostiquée chez $61.1 \%$ des patients dans le groupe $A$ et AT et chez $50 \%$ dans le groupe OAT $(p=0.6)$. La Varicocele a été retrouvée chez $33.3 \%$ des patients du groupe OAT et uniquement chez $22.2 \%$ dans le groupe A et AT $(p=0.6)$. Un facteur feminin associé a été mis en évidence chez $53.3 \%$ des patients du groupe $T$ (vs $27,7 \%$ dans $A$ et $A T$, et $41,6 \%$ dans OAT, $p=0.1$ ). D'autres étiologies responsables de l'altération de la qualité du sperme dans notre population étudiée ont été identifiées : traumatisme testiculaire (4\%), anomalie génétique
$(2 \%)$, médicamenteuse ou maladie générale $(4 \%)$.

Discussion et Conclusions : Au terme de notre étude, nous pouvons conclure que l'infertilité secondaire masculine est essentiellement liée à une infection génitale ou à une varicocèle. L'effet délétère de ces pathologies sur les paramètres spermatiques et la qualité embryonnaire a été largement rapporté dans la littérature. Cependant, plusieurs couples présentent de nombreux facteurs associés responsables de l'infertilité secondaire (facteurs féminins). Ainsi, le diagnostic étiologique de l'infertilité secondaire masculine nécessite une approche méthodique et rigoureuse basée sur la confrontation des données cliniques, biologiques et ultrasonographiques.

\section{POSTER 76}

Implication du diabète dans les troubles de la reproduction masculine

A. BEN HAMIDA SELLAMI1,3, N. FEKI CHAKROUN1,3, B. BEN AYED2, N. ABID1, M. GUERMAZI2, A. BAHLOUL3, T. REBAI1, L. KESKES AMMAR1,3

1 Laboratoire d'Histologie et Biologie de la Reproduction, Faculté de Médecine de Sfax 2 Service de Gynécologie Obstétrique, CHU

Hédi Chaker, Sfax 3 Unité de recherche"infertilité masculine" CHU Habib Bourguiba, Sfax Tunisie Ikeskes@yahoo.fr sellamiafifa@yahoo.fr

Introduction : Le rôle du diabète dans les troubles de l'érection est une notion bien documentée dans la littérature; cependant, les effets du diabète sur les autres fonctions reproductives et sur la fertilité masculine sont de plus en plus discutés devant l'augmentation de la prévalence du diabète chez les jeunes. L'objectif de notre travail était d'évaluer l'impact de cette pathologie sur les caractéristiques des paramètres spermatiques chez l'homme infertile diabétique et d'analyser les troubles de la reproduction associés.

Matériel et méthodes : L'étude a porté sur 18 patients infertiles diabétiques (G1) et 16 patients non diabétiques, partenaires masculins de couples explorés pour infertilité d'origine féminine, constituant le groupe contrôle (G2). Nous avons analysé rétrospectivement les données cliniques et les paramètres du spermogramme dans les deux groupes et nous avons comparé les valeurs moyennes (test de student) et les fréquences (test chi2) à l'aide du logiciel SPSS version 11.0. La signification a été retenue pour des valeurs de $p<0.05$.

Résultats : L'âge moyen et la durée moyenne d'infertilité étaient statistiquement comparables dans les deux groupes d'étude. Cependant, le volume moyen de l'éjaculat était significativement plus faible dans $\mathrm{G} 1(2.1 \mathrm{ml}$ vs $4 \mathrm{ml}$ dans $\mathrm{G} 2$; $\mathrm{p}<0.001)$ et l'hypospermie (volume de l'éjaculat $<2 \mathrm{ml}$ ) était significativement $(p<0.001)$ plus fréquente dans $G 1(44.4 \%)$ que dans $G 2(6.2 \%)$. Les valeurs moyennes de la mobilité totale initiale (après 30 min du recueil du sperme) et tardive (après $4 \mathrm{H}$ du recueil du sperme) étaient significativement plus élevées dans $\mathrm{G} 2$ (48.8\% et $46,3 \%$ vs $40.3 \%$ et $34 \%$, respectivement ; $p<0.05$ ). Les valeurs moyennes de la mobilité progressive rapide (type "a") étaient également significativement plus élevées dans $\mathrm{G} 2$ que dans $\mathrm{G} 1$ après $30 \mathrm{~min}$ et $4 \mathrm{H}$ du recueil du sperme $(17.5 \%$ et $15,2 \%$ vs $12.3 \%$ et $7,6 \%$, respectivement ; $p=0.03$ ). Nous n'avons trouvé aucune différence significative entre $\mathrm{G} 1$ et $\mathrm{G} 2$ concernant la vitalité moyenne, le taux moyen de spermatozoïdes de morphologie normale et le nombre moyen de leucocytes. Cependant, nous avons constaté que la numération moyenne des spermatozoïdes était plus élevée dans $\mathrm{G} 1$ que dans $\mathrm{G} 2$, mais sans atteindre la signification $\left(122.6 \times 10^{6} / \mathrm{ml}\right.$ 
vs $64.410^{6} / \mathrm{ml}$ respectivement; $p=0,06$ ) ; le taux de flagelles enroulés était également plus élevé dans le groupe G1 $(20 \%$ vs $10 \%$; $\mathrm{p}=0.001$ ). Des troubles de l'érection ou de l'éjaculation étaient notés chez $38,8 \%(7 / 18)$ du groupe G1. Aucun trouble sexuel n'a été noté dans G2.

Discussion et Conclusion : Nos résultats sont conformes à certaines données de la littérature qui montrent que le diabète est responsable d'une altération modérée des paramètres spermatiques, portant essentiellement sur le volume spermatique et la mobilité des spermatozoïdes. D'autres études rapportent une altération de tous les paramètres spermatiques. Ces effets délétères du diabète pourraient être liés aux complications dégénératives vasculaires expliquant les anomalies de l'éjaculation et du volume spermatique ainsi que de la qualité du sperme, mais aussi neurologiques expliquant les troubles sexuels. Récemment, il a été rapporté une augmentation de la fragmentation de L'ADN spermatique chez le diabétique, liée probablement à un état de stress oxydatif impliqué dans la pathogénie des complications chroniques du diabète. Dans notre étude, l'augmentation des radicaux libres dans le sperme serait responsable de la diminution de la mobilité spermatique et de l'augmentation des taux de flagelles enroulés dans le groupe G1. L'altération du génome spermatique chez l'homme diabétique serait un facteur déterminant dans l'altération de la fertilité de l'homme diabétique. 